\title{
Proteomic Strategy for Identification of Proteins Responding to Cisplatin-Damaged DNA
}

Wenjuan Zeng ${ }^{\mathrm{a}, \mathrm{b}}$, Zhifeng Du ${ }^{\mathrm{a}}$, Qun Luo ${ }^{\mathrm{a}, \mathrm{b}}$, Yao Zhao ${ }^{\mathrm{a}}$, Yuanyuan Wang ${ }^{\mathrm{a}}$, Kui $\mathrm{Wu}^{\mathrm{a}}$, Feifei Jia $^{\mathrm{a}}$, Yanyan Zhang ${ }^{\mathrm{a}, *}$, Fuyi Wang ${ }^{\mathrm{a}, \mathrm{b}, \mathrm{c}, *}$

${ }^{a}$ Beijing National Laboratory for Molecular Sciences; National Centre for Mass Spectrometry in Beijing; CAS Key Laboratory of Analytical Chemistry for Living Biosystems, Institute of Chemistry, Chinese Academy of Sciences, Beijing 100190, P. R. China.

${ }^{\mathrm{b}}$ University of Chinese Academy of Sciences, Beijing 100049, P. R. China

${ }^{c}$ Basic Medical College, Shandong University of Chinese Traditional Medicine, Jinan 250355, P. R. China

E-mail: fuyi.wang@iccas.ac.cn; zhangyy0816@iccas.ac.cn

\section{Supporting Information}

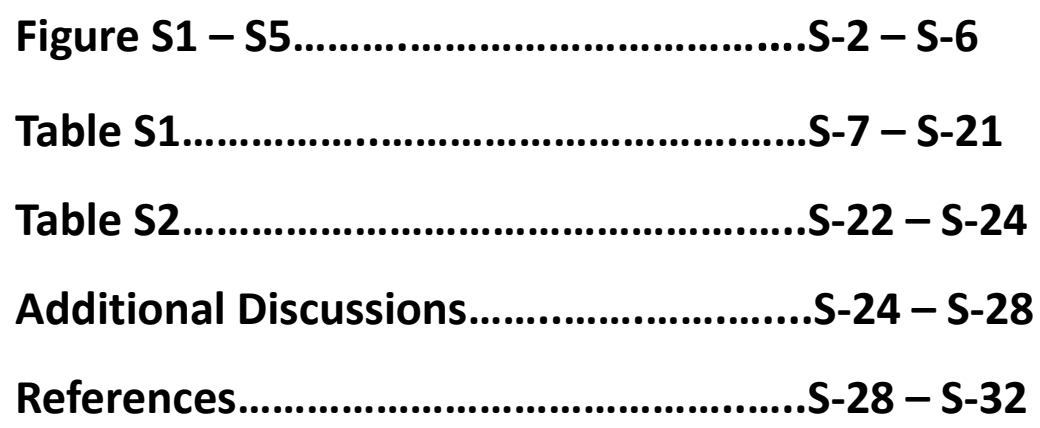




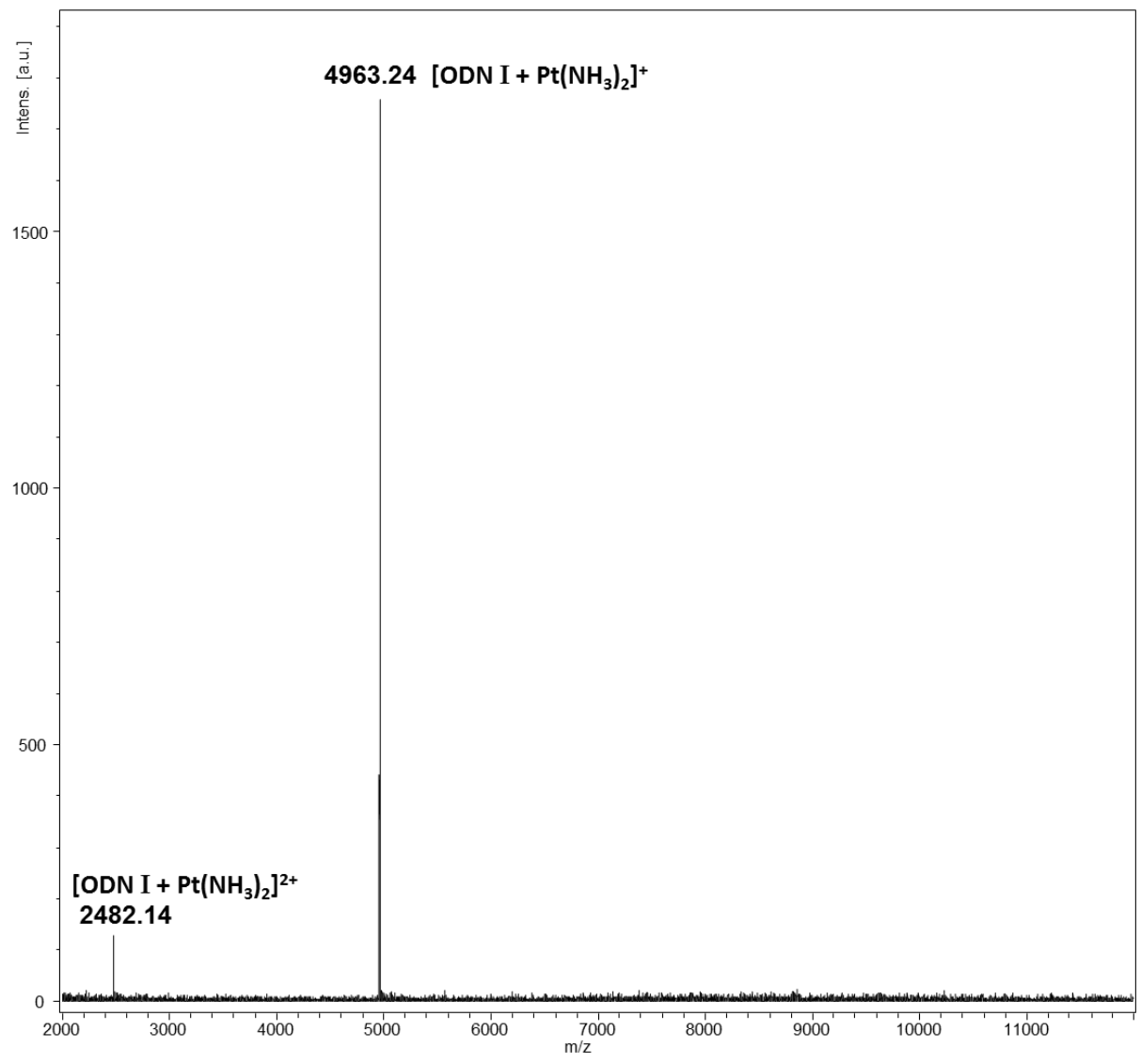

Figure S1. MALDI-TOF-MS spectrum of HPLC-purified ODN I crosslinked with cisplatin. 
(a)

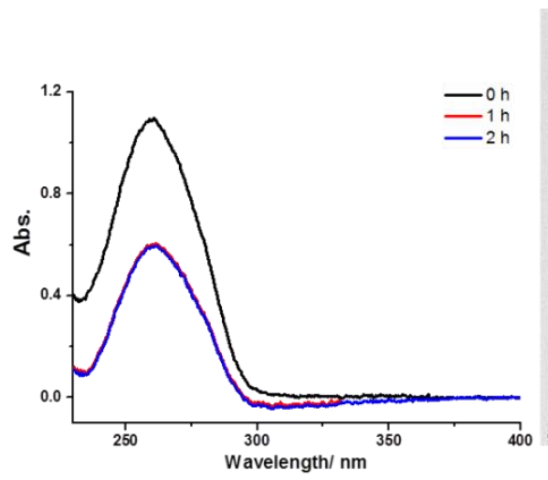

(b)

(c)

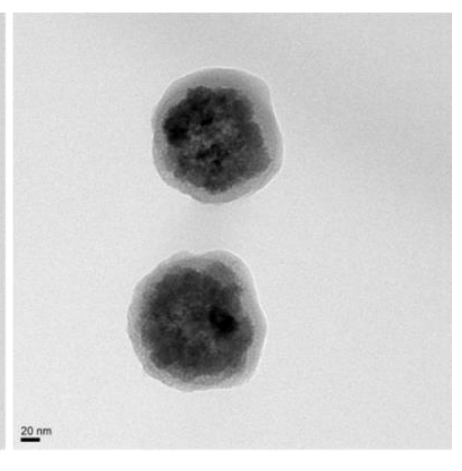

Figure S2. (a) UV absorption spectra of duplex ODN $\mathrm{N}_{3}$-III solution before (black line) and after click chemistry with MNPs for $1 \mathrm{~h}$ (red line) and $2 \mathrm{~h}$ (blue line). (b) and (c) TEM images of bare MNPs (b) and those conjugated with duplex ODN III (c). 

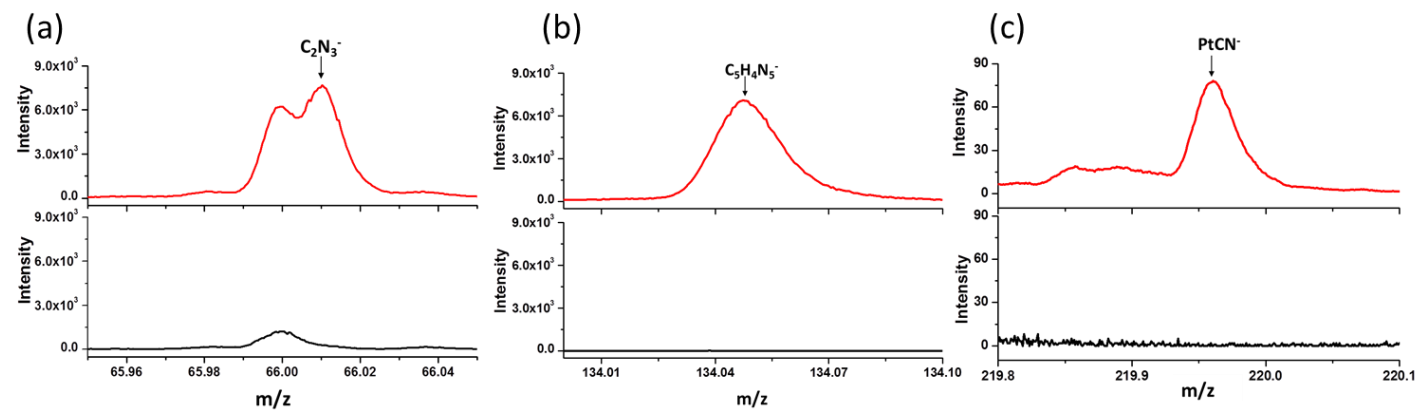

Figure S3. The surface chemical compositions of bare MNPs (bottom) and cisPt-III modified MNPs (top) characterized by time of flight secondary ion mass spectrometry (TOF-SIMS). The ion peak in the TOF-SIMS spectra of cisPt-III modified MNPs corresponds to (a) $\mathrm{C}_{2} \mathrm{~N}_{3}{ }^{-}$from triazole formed via click chemistry, (b) $\mathrm{C}_{5} \mathrm{H}_{4} \mathrm{~N}_{5}{ }^{-}$from adenine in ODN and (c) $\mathrm{PtCN}^{-}$from cisplatin-DNA adduct, respectively . 


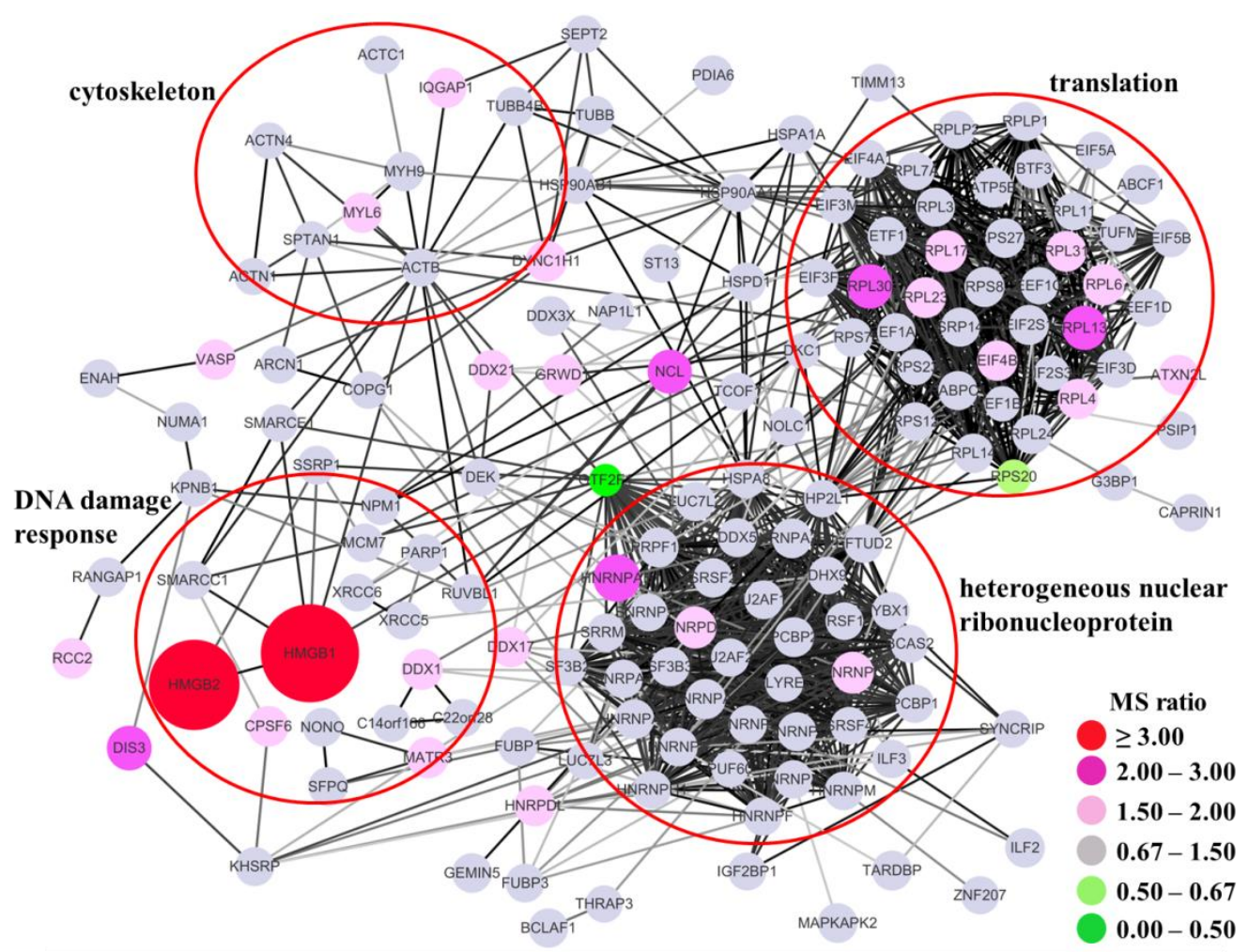

Figure S4. The protein-protein interaction (PPI) network generated by STRING 10.5 and visualized in Cytoscape 3.6.1. The PPI network consists of 152 proteins (nodes) connected by 1390 interactions (edges). The bigger node indicated a larger MS $\mathrm{H}_{\mathrm{Pos}} / \mathrm{L}_{\mathrm{Neg}}$ ratio $(0.00-11.00)$ and different colors were used to make the results more distinctive, for example, the red nodes represented proteins with a $\mathrm{H}_{\mathrm{Pos}} / \mathrm{L}_{\mathrm{Neg}}$ ratio $\geq$ 3.00 , the fuchsia $2.00-3.00$, the pink $1.50-2.00$, the grey $0.67-1.50$, the light green $0.50-0.67$ and the green $\leq 0.50$. Moreover, the darker edge indicated a higher combined score $(0.7-1.0)$ of the interaction. 


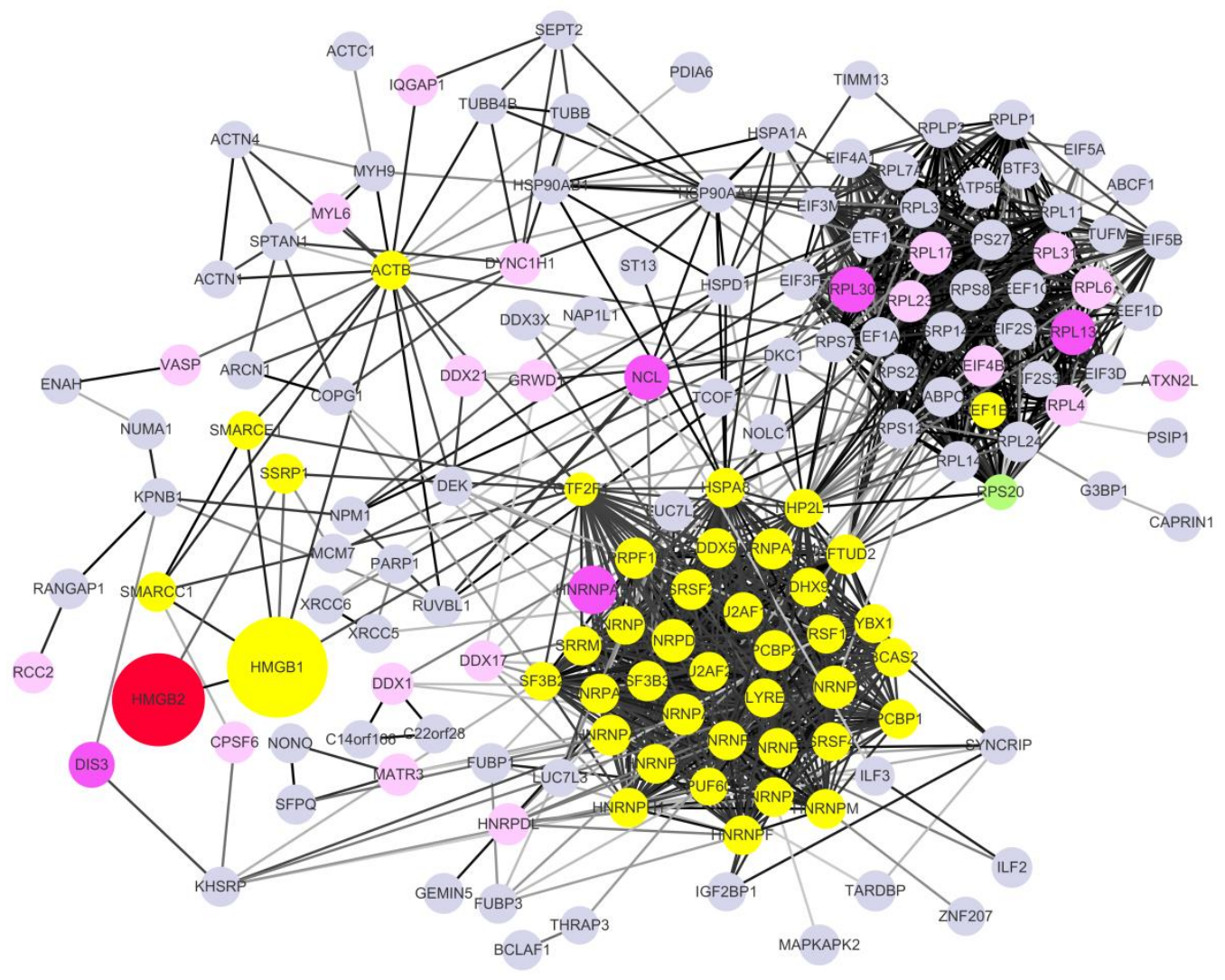

Figure S5. The first interaction neighbors (nodes filled with yellow) of TFIIFa in the protein-protein interaction (PPI) network of proteins responding to ODN damage by cisplatin. 
Table S1. A set of MS quantitative data for proteins captured by functionalized MNP probes

Note: 1. Pos $=$ CisPt-III modified MNPs; Neg= III modified MNPs; 2 . If only one tryptic peptide was used for the quantification of a protein, the corresponding mass spectrum is listed below the protein name; If more than one tryptic peptides were used for the quantification of a protein, no mass spectra are shown under the protein name.

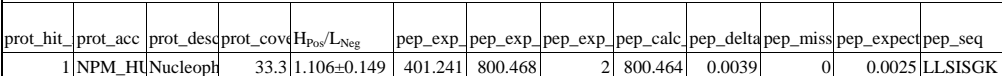

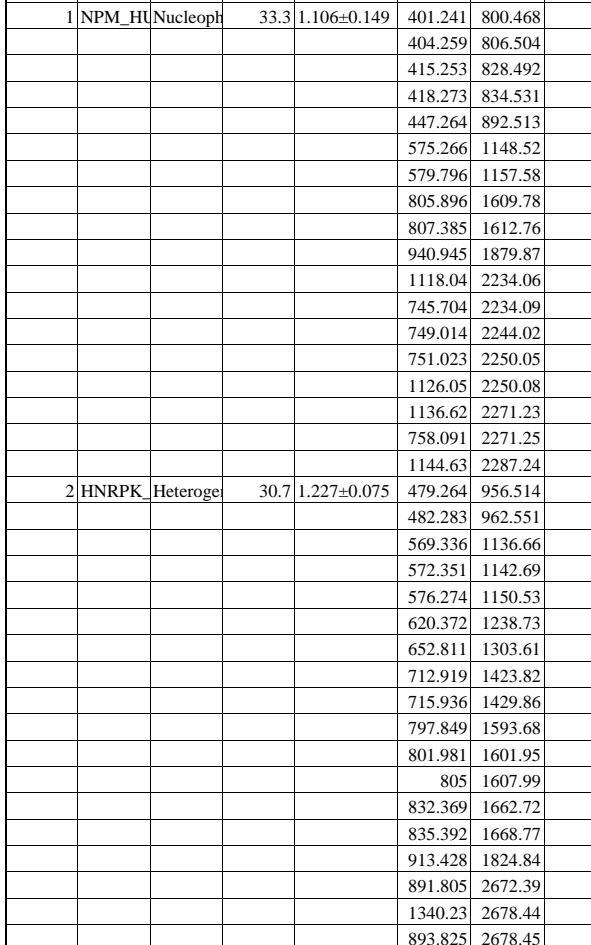

\begin{tabular}{l|l|l|l|l|l|l|}
3 & ROA2_H Heteroge & 39.4 & $1.424 \pm 0.112$ & 494.293 & 986.572 \\
\hline
\end{tabular}
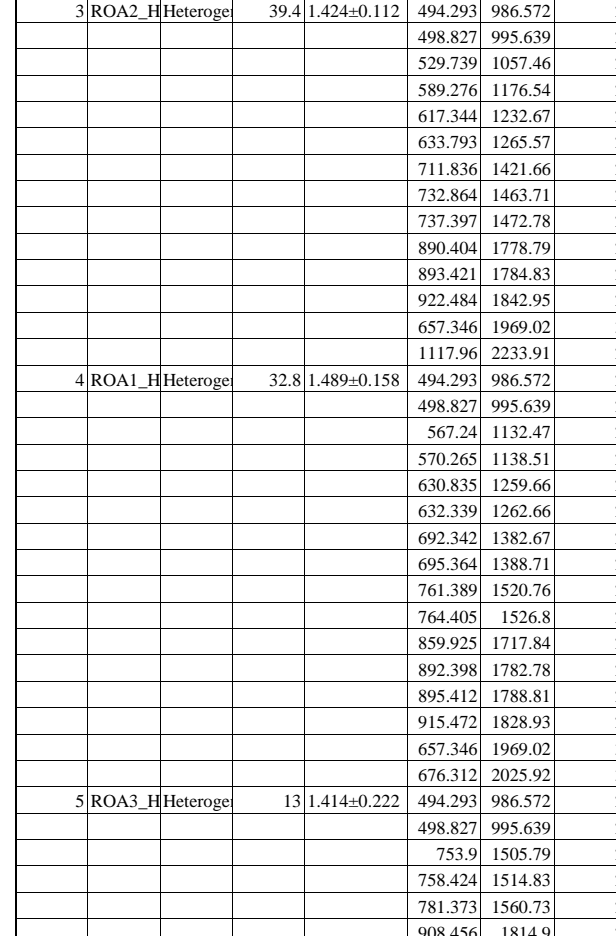

6 ROA0_H Heteroge $\quad 14.41 .215 \pm 0.326$

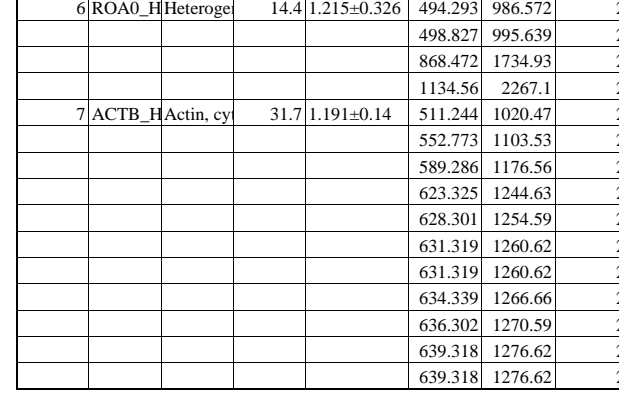

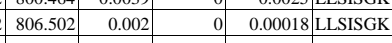

\begin{tabular}{l|l|l|l|l|l|l|}
2 & 828.496 & -0.0038 & 0 & 0.00012 & VTLATLK \\
\hline
\end{tabular}

\begin{tabular}{|r|r|r|r|r|r|}
834.533 & -0.0019 & 0 & 0.000011 & VTLATLK \\
\hline
\end{tabular}

\begin{tabular}{l|r|r|r|r|r|}
\hline 892.514 & -0.001 & 0 & 0.0019 & TVSLGAGAK \\
\hline
\end{tabular}

\begin{tabular}{l|l|l|l|l|l|l|l|l}
\hline 1148.51 & 0.0036 & 1 & 0.0018 & ADKDYHFK \\
\hline
\end{tabular}

\begin{tabular}{|l|l|l|l|l|l|l}
11157.57 & 0.0064 & 1 & 0.00027 & ADKDYHFK \\
\hline
\end{tabular}

\begin{tabular}{|c|c|c|c|c|}
\hline 1609.73 & 0.0437 \\
\hline
\end{tabular}

\begin{tabular}{|l|r|}
\hline 1612.75 & 0.004 \\
\hline
\end{tabular}

\begin{tabular}{|l|l|l|}
2 & 1879.86 & 0.0143 \\
\hline
\end{tabular}

\begin{tabular}{|l|l|r|}
2 & 2234.07 & -0.0095 \\
\hline & 2234.07 & 0.022
\end{tabular}

\begin{tabular}{ll|l}
2234.07 & 0.0221 \\
\hline
\end{tabular}

\begin{tabular}{|l|l|l|}
3 & 2244.03 & -0.0048 \\
\hline & 2250.06 & -0.0164
\end{tabular}

\begin{tabular}{ll|l|l|}
3 & 2250.06 & -0.0164 \\
\hline
\end{tabular}

\begin{tabular}{|r|r|r|}
\hline 2 & 2250.06 & 0.0132 \\
\hline
\end{tabular}

\begin{tabular}{|c|c|c|}
\hline & 2271.24 & -0.0056 \\
\hline & 2271.24 & 0.0146
\end{tabular}

\begin{tabular}{|l|l|}
\hline 2271.24 & 0.0146 \\
\hline
\end{tabular}

\begin{tabular}{|l|l|}
\hline 956.518 & -0.0041 \\
\hline
\end{tabular}

\begin{tabular}{l|l|l|l}
2 & 962.556 & -0.0043 \\
\hline
\end{tabular}

\begin{tabular}{|l|l|r|}
\hline & 1136.66 & 0.0012 \\
\hline
\end{tabular}

\begin{tabular}{|l|l|l|}
\hline 1142.69 & -0.0059 \\
\hline
\end{tabular}

\begin{tabular}{|l|r|r|}
2 & 1150.54 & -0.0038 \\
\hline
\end{tabular}

\begin{tabular}{|r|r|r|}
\hline 1238.72 & 0.007 \\
\hline
\end{tabular}

\begin{tabular}{|r|r|}
1303.6 & 0.0096 \\
\hline 1423.82 & 0.0054 \\
\hline
\end{tabular}

\begin{tabular}{|l|l|l|}
\hline & 1429.86 & 0.0024 \\
\hline
\end{tabular}

\begin{tabular}{|l|r|}
\hline 1593.67 & 0.0091 \\
\hline
\end{tabular}

\begin{tabular}{|l|l|l|}
\hline & 1601.95 & -0.0041 \\
\hline
\end{tabular}

\begin{tabular}{|l|l|l|}
\hline & 1607.99 & -0.0021 \\
\hline
\end{tabular}

\begin{tabular}{|l|l|l|}
\hline 1662.72 & 0.0043 \\
\hline
\end{tabular}

\begin{tabular}{|l|l|l|}
\hline 1668.76 & 0.0131 \\
\hline
\end{tabular}

\begin{tabular}{|l|l}
2672.4 & -0.0095 \\
\hline
\end{tabular}

\begin{tabular}{|l|r|}
2678.44 & 0.0051 \\
\hline
\end{tabular}

$2678.44 \quad 0.0133$

\begin{tabular}{|l|r|r|}
\hline & 986.58 & -0.008 \\
\hline
\end{tabular}

\begin{tabular}{|l|l|l|}
\hline & 1057.47 & -0.003 \\
\hline
\end{tabular}

\begin{tabular}{|r|r|r|}
\hline & 1176.54 & 0.002 \\
\hline & 1232.67 & 0.0045 \\
\hline
\end{tabular}

\begin{tabular}{|l|l|}
\hline 1265.57 & -0.0044 \\
\hline
\end{tabular}

\begin{tabular}{|l|l|}
\hline 1421.65 & 0.0057 \\
\hline
\end{tabular}

\begin{tabular}{|l|l|l|}
\hline & 1463.73 & -0.0119 \\
\hline
\end{tabular}

\begin{tabular}{|l|l|l|}
\hline & 1472.78 & -0.0029 \\
\hline
\end{tabular}

\begin{tabular}{|l|l|l|}
\hline 1778.78 & 0.0152 \\
\hline
\end{tabular}

\begin{tabular}{|l|l|l|}
\hline & 1784.82 & 0.0104 \\
\hline & 1842.94 & 0.0092 \\
\hline & 1969.02 & -0.0003
\end{tabular}

\begin{tabular}{|r|r|r|}
\hline 2 & 1842.94 & 0.0092 \\
\hline 3 & 1969.02 & -0.0003 \\
\hline
\end{tabular}

\begin{tabular}{|l|l|}
\hline 2233.93 & -0.0193 \\
\hline
\end{tabular}

\begin{tabular}{l|l|l}
\hline & 986.58 & -0.008 \\
\hline
\end{tabular}

\begin{tabular}{|l|r|r|}
\hline 995.637 & 0.0023 \\
\hline
\end{tabular}

\begin{tabular}{|r|r|r|}
\hline & 1132.47 & -0.0053 \\
\hline & 1138.51 & 0.0059 \\
\hline
\end{tabular}

\begin{tabular}{|l|l|l|}
\hline & 1138.51 & 0.0059 \\
\hline & 1259.64 & 0.0131 \\
\hline
\end{tabular}

\begin{tabular}{|l|l|l|}
\hline 2 & 1262.66 & 0.0012 \\
\hline
\end{tabular}

\begin{tabular}{|l|l|l|}
\hline & 1382.67 & 0.0024 \\
\hline
\end{tabular}

\begin{tabular}{|l|l|l|}
\hline 1388.71 & 0.0089 \\
\hline
\end{tabular}

\begin{tabular}{|l|l|l|}
\hline & 1520.76 & 0.0056 \\
\hline
\end{tabular}

\begin{tabular}{|l|l|l|}
\hline 1526.8 & 0.0003 \\
\hline
\end{tabular}

\begin{tabular}{|l|l|l|}
\hline & 1717.83 & 0.0029 \\
\hline & 1782.77 & 0.0085 \\
\hline
\end{tabular}

\begin{tabular}{|l|l|}
\hline 1782.77 & 0.0085 \\
\hline
\end{tabular}

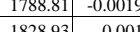

\begin{tabular}{|l|r|r|}
\hline 3 & 1828.93 & 0.001 \\
\hline 3 & 1969.02 & -0.0003 \\
\hline & 2025.91 & 0.0039 \\
\hline
\end{tabular}

\begin{tabular}{|r|r|r|}
\hline 3 & 1969.02 & -0.0003 \\
\hline 3 & 2025.91 & 0.0039 \\
\hline
\end{tabular}

\begin{tabular}{|r|r|}
\hline 986.58 & -0.008 \\
\hline
\end{tabular}

\begin{tabular}{|l|l|l|}
\hline & 995.637 & 0.0023 \\
\hline
\end{tabular}

\begin{tabular}{l|l|l|}
\hline & 1505.77 & 0.0134 \\
\hline
\end{tabular}

\begin{tabular}{|l|l|}
1514.83 & 0.0048 \\
\hline
\end{tabular}

\begin{tabular}{|l|l|l|}
\hline 1560.73 & 0.0046 \\
\hline
\end{tabular}

\begin{tabular}{|r|r|r|}
\hline & 1814.91 & -0.0154 \\
\hline & 986.58 & -0.008 \\
\hline
\end{tabular}

\begin{tabular}{|r|r|r|}
\hline & 986.58 & -0.008 \\
\hline & 995.637 & 0.0023 \\
\hline
\end{tabular}

\begin{tabular}{ll|l}
\hline & 1734.93 & -0.0058 \\
\hline
\end{tabular}

\begin{tabular}{|l|l|r|}
\hline 2267.09 & 0.017 \\
\hline
\end{tabular}

\begin{tabular}{|l|r|}
1020.47 & 0.0029 \\
\hline
\end{tabular}

\begin{tabular}{|l|l|l|}
\hline & 1103.53 & -0.0005 \\
\hline
\end{tabular}

\begin{tabular}{|l|l|l|}
2 & 1176.55 & 0.0087 \\
\hline 2 & 1244.63 & 0.0023 \\
\hline
\end{tabular}

\begin{tabular}{|l|l|l|}
\hline & 1244.63 & 0.0023 \\
\hline & 1254.58 & 0.0027 \\
\hline
\end{tabular}

\begin{tabular}{|l|l|}
\hline 1260.62 & 0.0013 \\
\hline
\end{tabular}

\begin{tabular}{lll}
1260.63 & -0.0033 \\
\hline
\end{tabular}

\begin{tabular}{|l|r|r|}
\hline & 1266.66 & -0.0006 \\
\hline
\end{tabular}

\begin{tabular}{|r|r|r|}
\hline 2 & 1270.58 & 0.009 \\
\hline 2 & 1276.62 & 0.0043 \\
\hline & 1276.62 & 0.0043
\end{tabular}

\begin{tabular}{|l|l|l|}
\hline & 1276.62 & 0.0043 \\
\hline & 1276.62 & 0.0043 \\
\hline
\end{tabular}

0.0013 DLAGSIIGK

0.0053 DLAGSIIGK

$\begin{array}{ll}0 & 0.000032 \\ & \text { VVLIGGKPDR }\end{array}$

1. 0.0074 KLFVGGIK

0.0033 KLFVGGIK

0.0079 GGNFGFGDSR

0.00075 NYYEQWGK

\begin{tabular}{l|l|l|l}
0 & 0.00065 & IDTIEIITDR
\end{tabular}

0.0074 KIFVGGIK

0.0033 KIFVGGIK

0.00055 DYFEQYGK

\begin{tabular}{l|r|r|}
0 & 0.00014 & DYFEQYGK
\end{tabular}

\begin{tabular}{l|l}
0 & $2.7 \mathrm{E}-06$ \\
IEVIEIMTDR
\end{tabular}

0 $5.7 \mathrm{E}-06$ IEVIEIMTDR

10.0074 KIFVGGIK

\begin{tabular}{l|l|l|l|}
1 & 0.0033 & KIFVGGIK \\
\hline
\end{tabular}

$1 \quad 0.0074$ KLFVGGLK

0.0033 KLFVGGLK

0.00042 DLTDYLMK

0.00051 GYSFTTTAER \begin{tabular}{|c|c|}
\hline 995.637 & 0.0023 \\
\hline
\end{tabular}
0.00027 ADKDYHFK

\begin{tabular}{r|r|r|}
\hline 0.0042 & VDNDENEHQLSLR \\
\hline & $2.6 \mathrm{E}-08$ & VDNDENEHQLSLR \\
\hline
\end{tabular}

\begin{tabular}{l|l|l}
0 & $1.5 \mathrm{E}-08$ & MTDQEAIQDLWQWR
\end{tabular}

8.3E-07 DELHIVEAEAMNYEGSPIK

3.3E-08 DELHIVEAEAMNYEGSPIK

\begin{tabular}{|r|l|l|l|}
\hline 0.0037 & DELHIVEAEAMNYEGSPIK & Oxidation (M); Acetyl (N-term); Acetyl (K) & \\
\hline $1.9 \mathrm{E}-06$ & DELHIVEAEAMNYEGSPIK & Oxidation (M); Acetyl:2H(3) (N-term); Acetyl:2H(3) (K)
\end{tabular}

\begin{tabular}{l|l|l|l}
\hline 0 & $3.8 \mathrm{E}-09$ & DELHIVEAEAMNYEGSPIK & Oxidation (M); Acetyl:2H(3) (N-term); Acetyl:2H(3) (K)
\end{tabular}

0 1.3E-09 MSVQPTVSLGGFEITPPVVLR Acetyl:2H(3) (N-term)

2.9E-06 MSVQPTVSLGGFEITPPVVLR Acetyl:2H(3) (N-term)

1.1E-10 MSVQPTVSLGGFEITPPVVLR Oxidation (M): Acetyl:2H(3) (N-term)

0.000076 VVLIGGKPDR

\begin{tabular}{l|l}
0 & 0.0014 \\
\hline
\end{tabular}

0 0.00037 NLPLPPPPPPR

0.000023 IDEPLEGSEDR

0 $5.4 \mathrm{E}-07$ IILDLISESPIK

9.7E-07 ILDDLISESPIK

\begin{tabular}{l|l|l}
0 & 0.000012 & LFQECCPHSTDR \\
\hline & 0.000011 & LLISLAGCIGVK
\end{tabular}

0.000011 LLIHQSLAGGIIGVK

\begin{tabular}{l|l}
0 & $4.8 \mathrm{E}-08$ \\
LLIHQSLAGGIIGVK
\end{tabular}

0.00002 RPAEDMEEEQAFK

0.000024 RPAEDMEEEQAFK

\begin{tabular}{l|r|r|}
0 & 0.000024 & RPAEDMEEEQAFK \\
\hline 0 & $7.4 \mathrm{E}-06$ & TDYNASVSVPDSSGPER
\end{tabular}

Acetyl $(\mathrm{N}$-term); Acetyl (K)

Acetyl:2H(3) (N-term); Acetyl:2H(3) (K)

Acetyl (N-term); Acetyl (K)

Acetyl:2H(3) (N-term); Acetyl:2H(3) (K)

Acetyl:2H(3) (N-term)

Acetyl:2H(3) (N-term)

Acetyl:2H(3) (N-term)

Acetyl (N-term); Acetyl (K)

Acetyl:2H(3) (N-term); Acetyl:2H(3) (K)

Acetyl:2H(3) (N-term)

Acetyl (N-term); Acetyl (K)

Acetyl:2H(3) (N-term); Acetyl:2H(3) (K)

Acetyl (N-term); Acetyl (K)

0.00047 IITITGTQDQIQNAQYLLQNSYAcetyl (N-term); Acetyl (K)

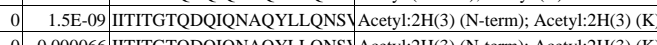

00.000066 IITITGTQDQIQNAQYLLQNS 4 Acetyl:2H(3) (N-term); Acetyl:2H(3) (K)

\begin{tabular}{l|l|l|l}
0 & 0.000012 & QEMQEVQSSR
\end{tabular}

$\begin{array}{lll}0 & 7.8 \mathrm{E}-06 & \text { GGGGNFGPGPGSNFR }\end{array}$

0.00017 EESGKPGAHVTVK

0.00037 EESGKPGAHVTVK

\begin{tabular}{l|l}
0 & 0.000017 \\
GFGFVTFDDHDPVDK
\end{tabular}

9E-07 GFGFVTFDDHDPVDK

1.9E-08 LFIGGLSFETTEESLR

10.0002 LFVGGIKEDTEEHHLR

Acetyl:2H(3) (N-term); Acetyl:2H(3) (K)

10.000013 SESPKEPEQLR

0.0003 SESPKEPEQLR

\begin{tabular}{l|l|l|}
0 & 0.000074 & EDSQRPGAHLTVK
\end{tabular}

0.000056 EDSQRPGAHLTVK

\begin{tabular}{l|l}
0 & $3.7 \mathrm{E}-08$ \\
\hline
\end{tabular}

\begin{tabular}{l|l|l}
0 & $1.9 \mathrm{E}-06$ & GFAFVTFDDHDSVDK
\end{tabular}

\begin{tabular}{l|l|l}
0 & $1.8 \mathrm{E}-06$ & GFAFVTFDDHDSVDK
\end{tabular}

3.6E-08 LFIGGLSFETTDESLR

0.0002 IFVGGIKEDTEEHHLR

\begin{tabular}{l|l|l|l|l|l|}
\hline 0 & $4.5 \mathrm{E}-06$ & SHFEQWGTLTDCVVMR
\end{tabular}

0.0026 EDSVKPGAHLTVK

0.000091 EDSVKPGAHLTVK

0.0065 YHTINGHNCEVK

3.6E-09 LFIGGLSFETTDDSLR

2.1E-08 LFIGGLNVQTSESGLR

Acetyl (N-term); 2 Acetyl (K)

Acetyl:2H(3) (N-term); 2 Acetyl:2H(3) (K)

Acetyl: $2 \mathrm{H}(3)(\mathrm{N}$-term)

Acetyl:2H(3) (N-term); Acetyl:2H(3) (K)

Acetyl:2H(3) (N-term)

Acetyl:2H(3) (N-term)

cetyl:2H(3) (N-term)

Acetyl (N-term); 2 Acetyl (K)

Acetyl:2H(3) (N-term); 2 Acetyl:2H(3) (K)

Acetyl (N-term); Acetyl (K)

Acetyl:2H(3) (N-term); Acetyl:2H(3) (K)

(N-term)

Sicetyl:2H(3) (N-term)

Acetyl (N-term); 2 Acetyl (K)

Acetyl:2H(3) (N-term); 2 Acetyl:2H(3) (K)

Acetyl (N-term); Acetyl (K)

Acetyl:2H(3) (N-term); Acetyl:2H(3) (K)

Acetyl (N-term)

Acetyl:2H(3) (N-term)

Acetyl (N-term); Acetyl (K)

Acetyl:2H(3) (N-term); Acetyl:2H(3) (K)

Acetyl (N-term); Acetyl (K)

Acetyl:2H(3) (N-term); Acetyl:2H(3) (K)

Acetyl:2H(3) (N-term); Acetyl:2H(3) (K)

Acetyl (N-term); Acetyl (K)

Acetyl:2H(3) (N-term); Acetyl:2H(3) (K)

Acetyl:2H(3) (N-term)

Acetyl:2H(3) (N-term); Acetyl:2H(3) (K)

Oxidation (M); Acetyl:2H(3) (N-term)

Acetyl (N-term); 2 Acetyl (K)

Acetyl:2H(3) (N-term); 2 Acetyl:2H(3) (K)

Acetyl (N-term); 2 Acetyl (K)

Acetyl:2H(3) (N-term); 2 Acetyl:2H(3) (K)

Acetyl:2H(3) (N-term); Acetyl:2H(3) (K)

Acetyl:2H(3) (N-term)

Acetyl (N-term); 2 Acetyl (K)

Acetyl:2H(3) (N-term); 2 Acetyl:2H(3) (K)

\begin{tabular}{l|l|l|}
\hline 4.3E-07 GDVAEGDLIEHFSQFGTVEK & Acetyl:2H(3) (N-term) \\
\hline
\end{tabular}

0 0.00003 AGFAGDDAPR

\begin{tabular}{l|l|l}
0 & 0.00017 & EITALAPSTMK \\
\hline & $5.5 \mathrm{E}-06$ & $\mathrm{LQGVMVGMGQK}$ \\
\hline
\end{tabular}

\begin{tabular}{l|l|l}
0 & $5.5 \mathrm{E}-06$ & HQGVMVGMGQK
\end{tabular}

0 3.7E-08 HQGVMVGMGQK

\begin{tabular}{l|l|l}
0 & $6.1 \mathrm{E}-06$ & EITALAPSTMK \\
\hline
\end{tabular}

\begin{tabular}{l|l}
0 & 0.0013 \\
EITALAPSTMK
\end{tabular}

\begin{tabular}{l|l}
0 & $9.1 \mathrm{E}-07$ \\
$\mathrm{HQGVMVGMGQK}$
\end{tabular}

2.7E-06 HQGVMVGMGQK \begin{tabular}{l|r|r|}
0 & 0.000019 & HQGVMVGMGQK \\
\hline
\end{tabular}
Acetyl:2H(3) (N-term);

Oxidation (M); Acetyl:2H(3) (N-term); Acetyl:2H(3) (K)

Acetyl:2H(3) (N-term)

Acetyl (N-term); Acetyl (K)

Acetyl (N-term); Acetyl (K)

Acetyl:2H(3) (N-term); Acetyl:2H(3) (K)

Oxidation (M); Acetyl (N-term); Acetyl (K)

Oxidation (M); Acetyl (N-term); Acetyl (K)

\begin{tabular}{l} 
Oxidation (M); Acetyl:2H(3) (N-term); Acetyl:2H(3) (K) \\
\hline Oxidation (M); Acetyl:2H(3) (N-term); Acetyl:2H(3) (K) \\
\hline
\end{tabular}
Oxidation (M); Acetyl:2H(3) (N-term); Acetyl:2H(3) (K) 


\begin{tabular}{|c|c|c|}
\hline & & \\
\hline & & \\
\hline & & \\
\hline & & \\
\hline & & \\
\hline & & \\
\hline & & \\
\hline & & \\
\hline 8 & ACTC_H & Actin, aln \\
\hline & & \\
\hline & & \\
\hline & & \\
\hline & & \\
\hline & & \\
\hline & & \\
\hline & & \\
\hline & & \\
\hline & & \\
\hline & & \\
\hline & & \\
\hline & & \\
\hline & & \\
\hline & & \\
\hline 9 & TBB5_H & Tubulin $\mathrm{E}$ \\
\hline & & \\
\hline & & \\
\hline & & \\
\hline & & \\
\hline & & \\
\hline & & \\
\hline & & \\
\hline & & \\
\hline & & \\
\hline & & \\
\hline & & \\
\hline & & \\
\hline & & \\
\hline & & \\
\hline & & \\
\hline & & \\
\hline & & \\
\hline & & \\
\hline & & \\
\hline 10 & TBB4B_ & Tubulin $\mathrm{H}$ \\
\hline & & \\
\hline & & \\
\hline & & \\
\hline & & \\
\hline & & \\
\hline & & \\
\hline & & \\
\hline & & \\
\hline & & \\
\hline & & \\
\hline & & \\
\hline & & \\
\hline & & \\
\hline & & \\
\hline & & \\
\hline & & \\
\hline & & \\
\hline & & \\
\hline 11 & NONO_H & Non-POL \\
\hline & & \\
\hline & & \\
\hline & & \\
\hline & & \\
\hline & & \\
\hline & & \\
\hline & & \\
\hline & & \\
\hline & & \\
\hline & & \\
\hline & & \\
\hline & & \\
\hline & & \\
\hline & & \\
\hline & & \\
\hline & & \\
\hline $12 \mathrm{~s}$ & SFPQ_H & Splicing \\
\hline & & \\
\hline & & \\
\hline & & \\
\hline & & \\
\hline & & \\
\hline & & \\
\hline & & \\
\hline & & \\
\hline & & \\
\hline & & \\
\hline & & \\
\hline & & \\
\hline & & \\
\hline $13 \mathrm{H}$ & FUBP1_ & ar upstra \\
\hline & & \\
\hline & & \\
\hline
\end{tabular}




\begin{tabular}{|c|c|c|}
\hline & & \\
\hline & & \\
\hline & & \\
\hline & & \\
\hline & & \\
\hline & & \\
\hline & & \\
\hline & & \\
\hline & & \\
\hline & & \\
\hline & & \\
\hline & & \\
\hline & & \\
\hline & & \\
\hline 14 & 4 FUBP3_1 & Far upstra \\
\hline & & \\
\hline & & \\
\hline & & \\
\hline 15 & \begin{tabular}{|l|l|} 
PARB_H \\
\end{tabular} & Plasmino \\
\hline & & \\
\hline & & \\
\hline & & \\
\hline & & \\
\hline & & \\
\hline & & \\
\hline & & \\
\hline 16 & \begin{tabular}{|l|l} 
RLA2_H \\
\end{tabular} & $160 \mathrm{~S}$ acidi \\
\hline & & \\
\hline & & \\
\hline & & \\
\hline & & \\
\hline 17 & 7 HNRH1 & Heteroge \\
\hline & & \\
\hline & & \\
\hline & & \\
\hline & & \\
\hline & & \\
\hline & & \\
\hline 18 & \begin{tabular}{|l|} 
HNRPF \\
\end{tabular} & Heteroge \\
\hline & & \\
\hline & & \\
\hline & & \\
\hline 19 & HSP7C_ & Heat shoo \\
\hline & & \\
\hline & & \\
\hline & & \\
\hline & & \\
\hline & & \\
\hline & & \\
\hline & & \\
\hline & & \\
\hline & & \\
\hline 20 & HS71A_H & Heat shoo \\
\hline & & \\
\hline & & \\
\hline & & \\
\hline & & \\
\hline & & \\
\hline & & \\
\hline & & \\
\hline 21 & 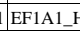 & Elongatio \\
\hline & & \\
\hline & & \\
\hline & & \\
\hline & & \\
\hline 22 & DDX3X & ATP-dep \\
\hline & & \\
\hline & & \\
\hline & & \\
\hline & & \\
\hline & & \\
\hline 23 & HNRPU & Heteroge \\
\hline & & \\
\hline & & \\
\hline & & \\
\hline & & \\
\hline & & \\
\hline & & \\
\hline 24 & 4 IMB1_H & Importin \\
\hline & & \\
\hline & & \\
\hline & & \\
\hline & & \\
\hline & & \\
\hline & & \\
\hline 25 & \begin{tabular}{|l|} 
HNRPL \\
\end{tabular} & Heteroge \\
\hline & & \\
\hline & & \\
\hline & & \\
\hline & & \\
\hline 26 & 6 HS90A_B & Heat shoo \\
\hline & & \\
\hline & & \\
\hline & & \\
\hline & & \\
\hline & & \\
\hline
\end{tabular}




\begin{tabular}{|c|c|c|}
\hline & & \\
\hline & & \\
\hline & & \\
\hline 27 & HS90B & Heat shoo \\
\hline & & \\
\hline & & \\
\hline & & \\
\hline & & \\
\hline & & \\
\hline & & \\
\hline & & \\
\hline & & \\
\hline & & \\
\hline & & \\
\hline 28 & \begin{tabular}{|l|l|} 
IF4A1_H \\
\end{tabular} & HEukaryot: \\
\hline & & \\
\hline & & \\
\hline & & \\
\hline 29 & \begin{tabular}{|l|l} 
CCl24_H \\
\end{tabular} & H Coiled-ce \\
\hline & & \\
\hline & & \\
\hline & & \\
\hline 30 & \begin{tabular}{|l|l} 
FUBP2_ \\
\end{tabular} & Far upstre \\
\hline & & \\
\hline & & \\
\hline & & \\
\hline & & \\
\hline & & \\
\hline & & \\
\hline & & \\
\hline 31 & 1 TCP4_H & II Activated \\
\hline & & \\
\hline & & \\
\hline & & \\
\hline 32 & \begin{tabular}{|l|l|} 
CH \\
\end{tabular} & 160 kDa h \\
\hline & & \\
\hline & & \\
\hline 33 & \begin{tabular}{|l|l} 
\\
\end{tabular} & \begin{tabular}{l|l}
$A$ \\
\end{tabular} \\
\hline & & \\
\hline & & \\
\hline & & \\
\hline & & \\
\hline 34 & \begin{tabular}{|l|l}
4 & RL6_Hu \\
\end{tabular} & 60 ribos \\
\hline & & \\
\hline & & \\
\hline & & \\
\hline 35 & \begin{tabular}{|l|l} 
PABP1_ \\
\end{tabular} & Polyaden \\
\hline & & \\
\hline & & \\
\hline & & \\
\hline & & \\
\hline 36 & \begin{tabular}{|l|l|} 
& EIF3F_H \\
\end{tabular} & Eukaryot \\
\hline & & \\
\hline & & \\
\hline & & \\
\hline 37 & \begin{tabular}{|l|l|} 
CPSF6_H \\
\end{tabular} & ICleavage \\
\hline & & \\
\hline & & \\
\hline & & \\
\hline 38 & \begin{tabular}{|l|l|} 
HMGA1 \\
\end{tabular} & High mol \\
\hline & & \\
\hline 39 & DDX1_H & ATP-dep \\
\hline & & \\
\hline & & \\
\hline & & \\
\hline 40 & \begin{tabular}{|l|l|} 
& RU2A_H
\end{tabular} & U2 small \\
\hline & & \\
\hline 41 & |RS8_HU & 140S ribos \\
\hline & & \\
\hline & & \\
\hline 42 & SF3B3_H & Splicing \\
\hline & & \\
\hline & & \\
\hline & & \\
\hline 43 & 3 HMGB1 & High mol \\
\hline & & \\
\hline & & \\
\hline 44 & \begin{tabular}{|l|l}
4 \\
PDIA6_H
\end{tabular} & Protein d \\
\hline & & \\
\hline & & \\
\hline 45 & \begin{tabular}{|l|l}
5 & ACTN \\
\end{tabular} & Alpha-ac \\
\hline & & \\
\hline & & \\
\hline & & \\
\hline & & \\
\hline & & \\
\hline 46 & \begin{tabular}{|l|l|}
6 & ACTN \\
\end{tabular} & Alpha-ac \\
\hline & & \\
\hline & & \\
\hline & & \\
\hline & & \\
\hline 47 & 7 F10A1_H & H Hsc70-in \\
\hline & & \\
\hline & & \\
\hline 48 & \begin{tabular}{|l|}
8 \\
\end{tabular} & Caprin-1 \\
\hline & & \\
\hline
\end{tabular}




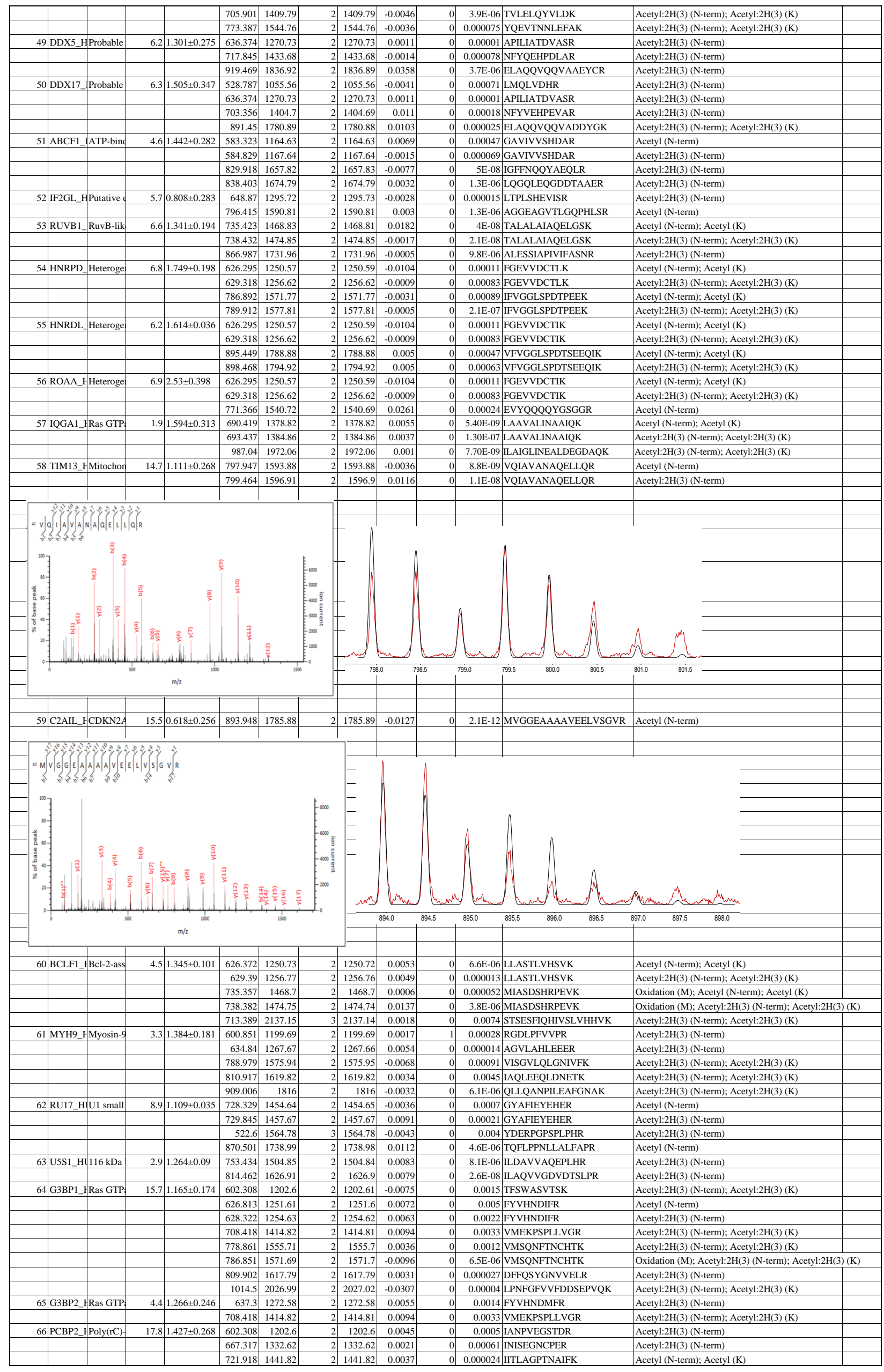




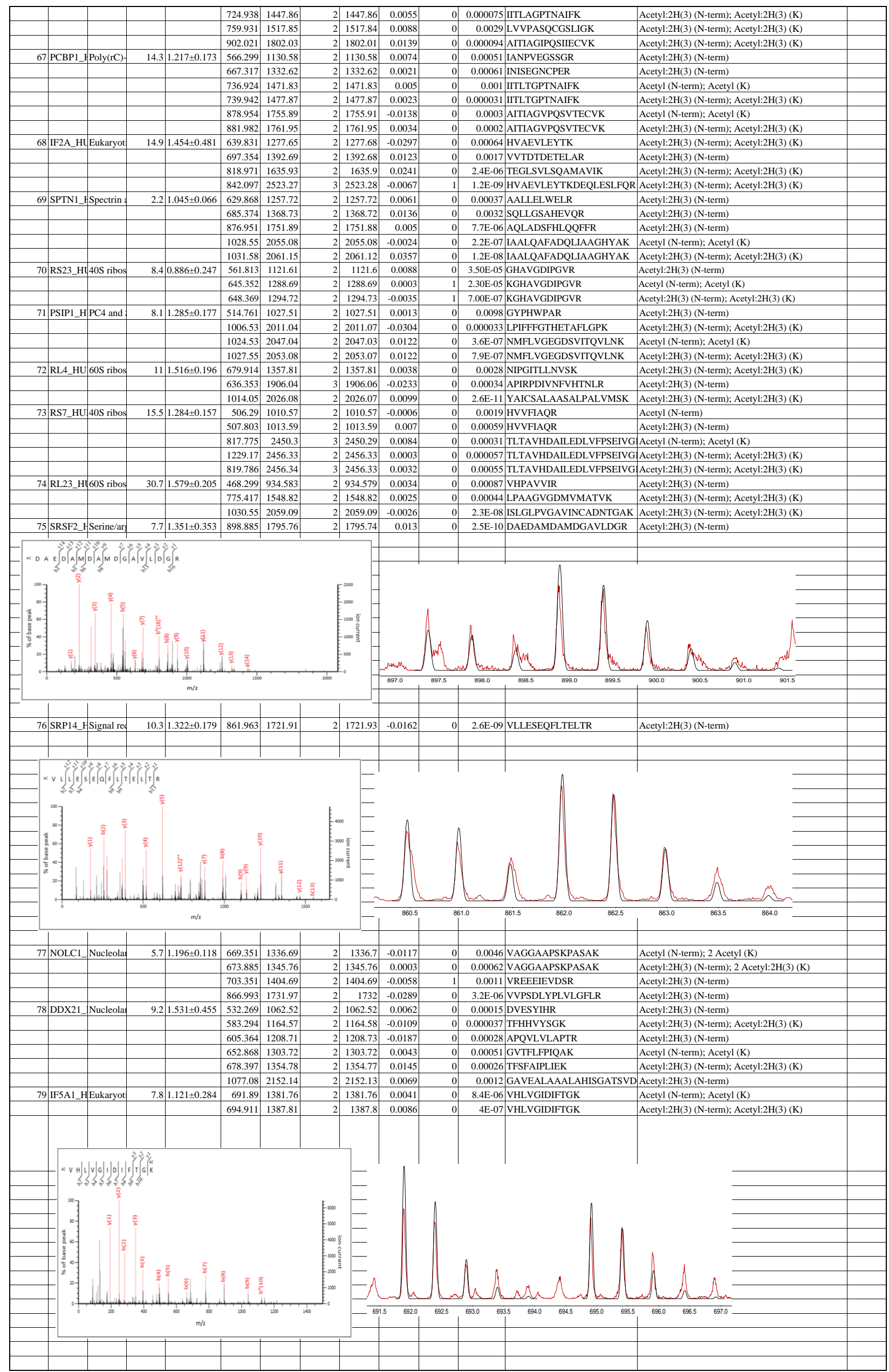




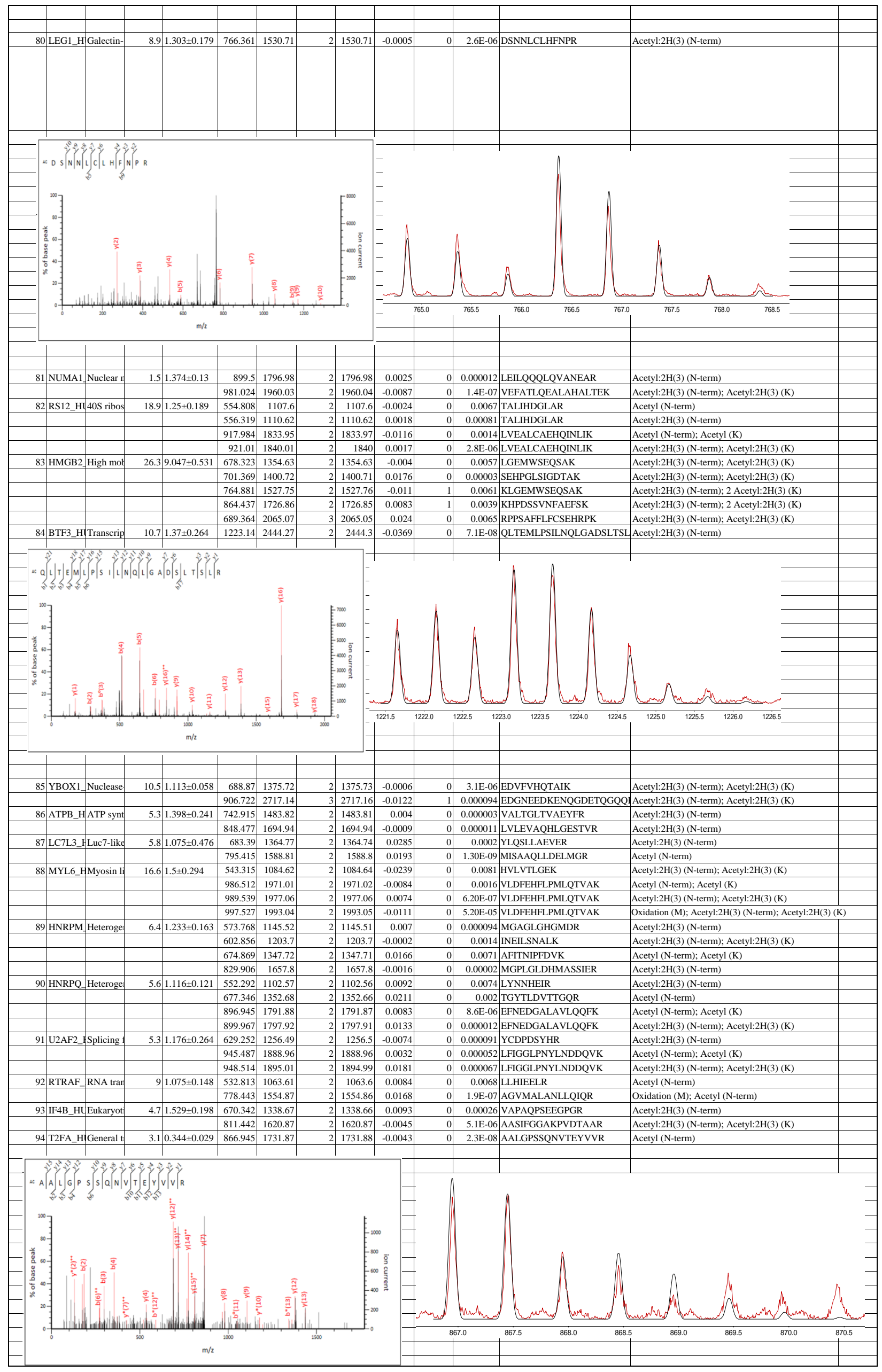




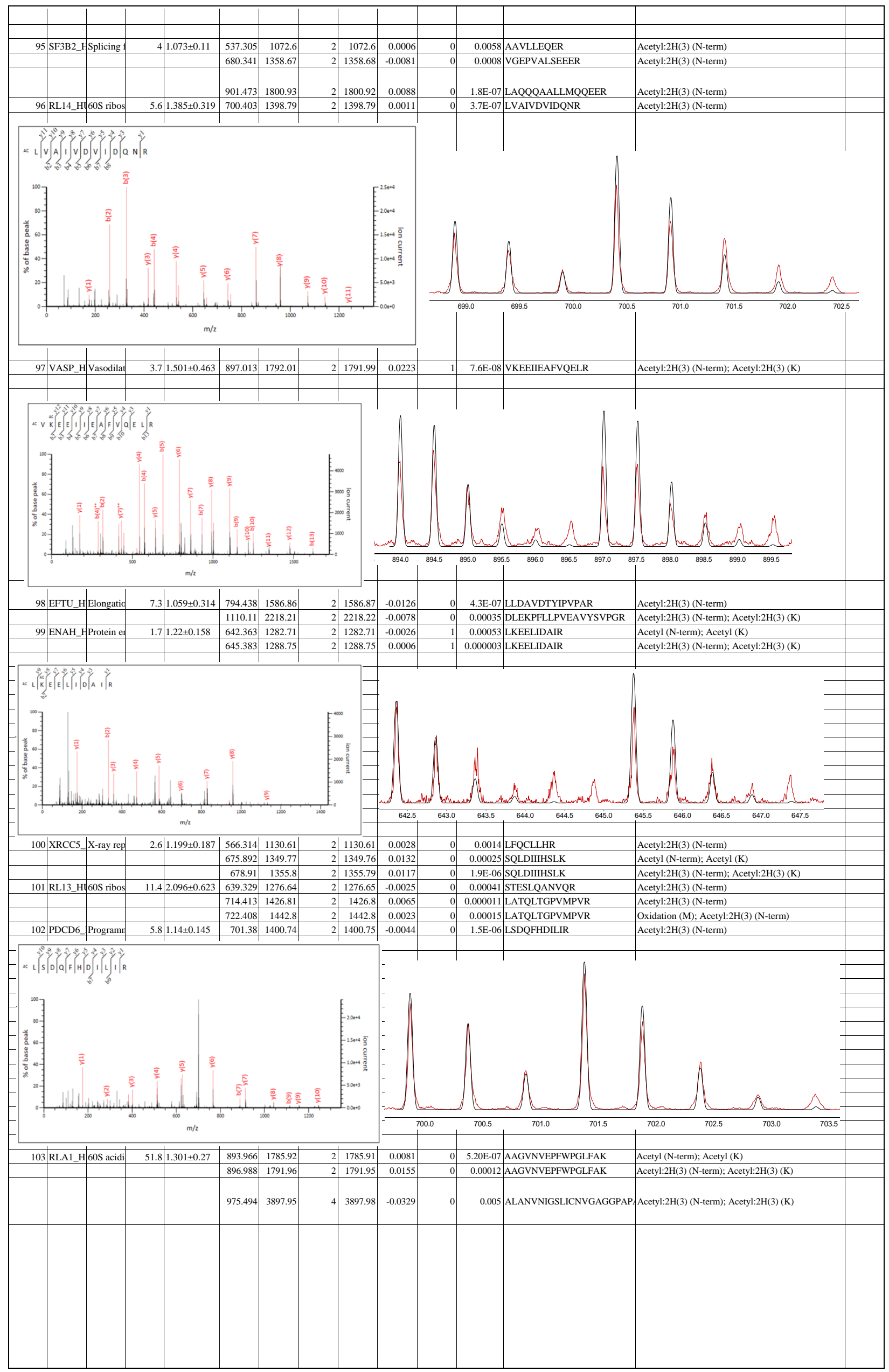




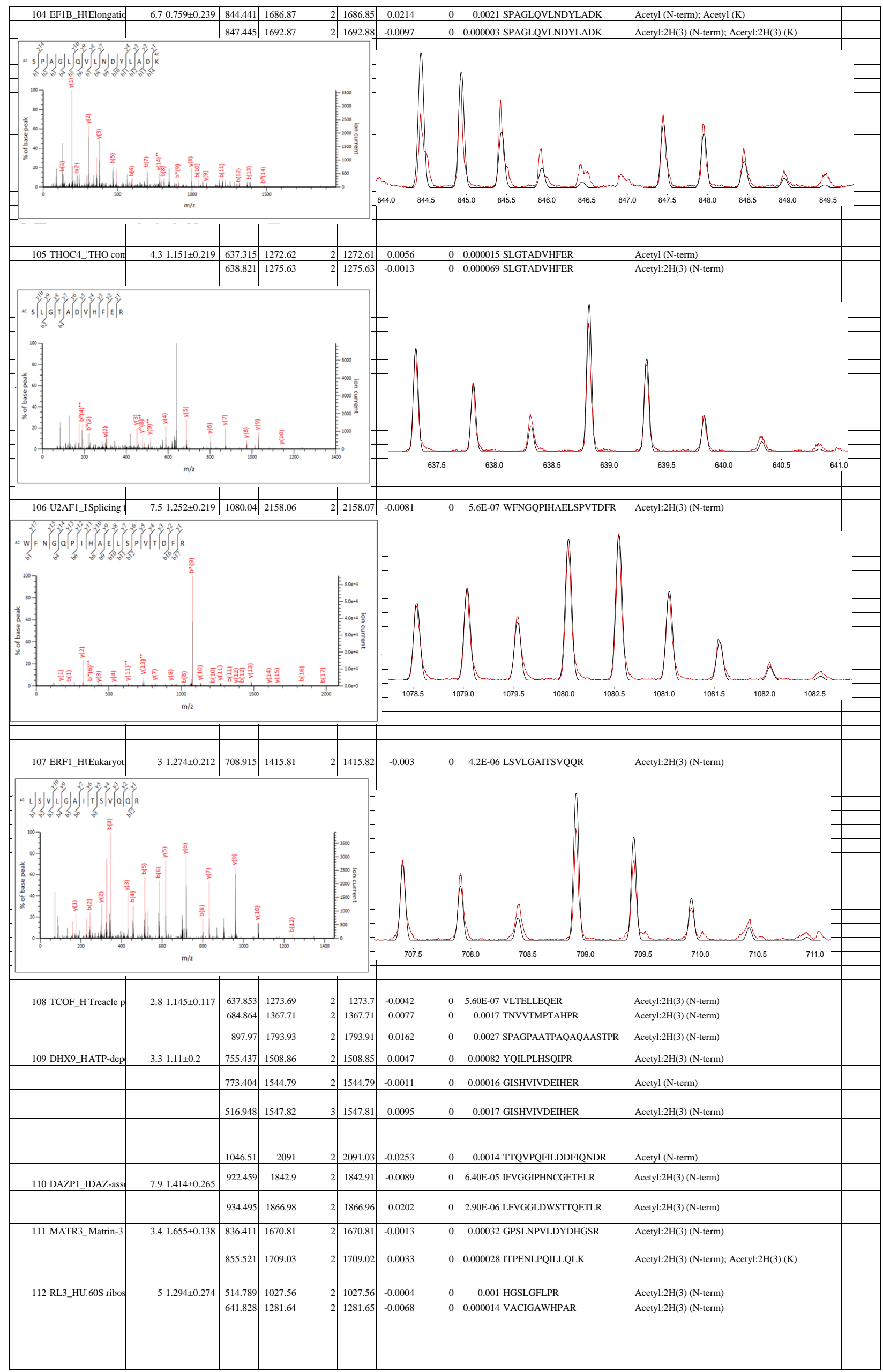




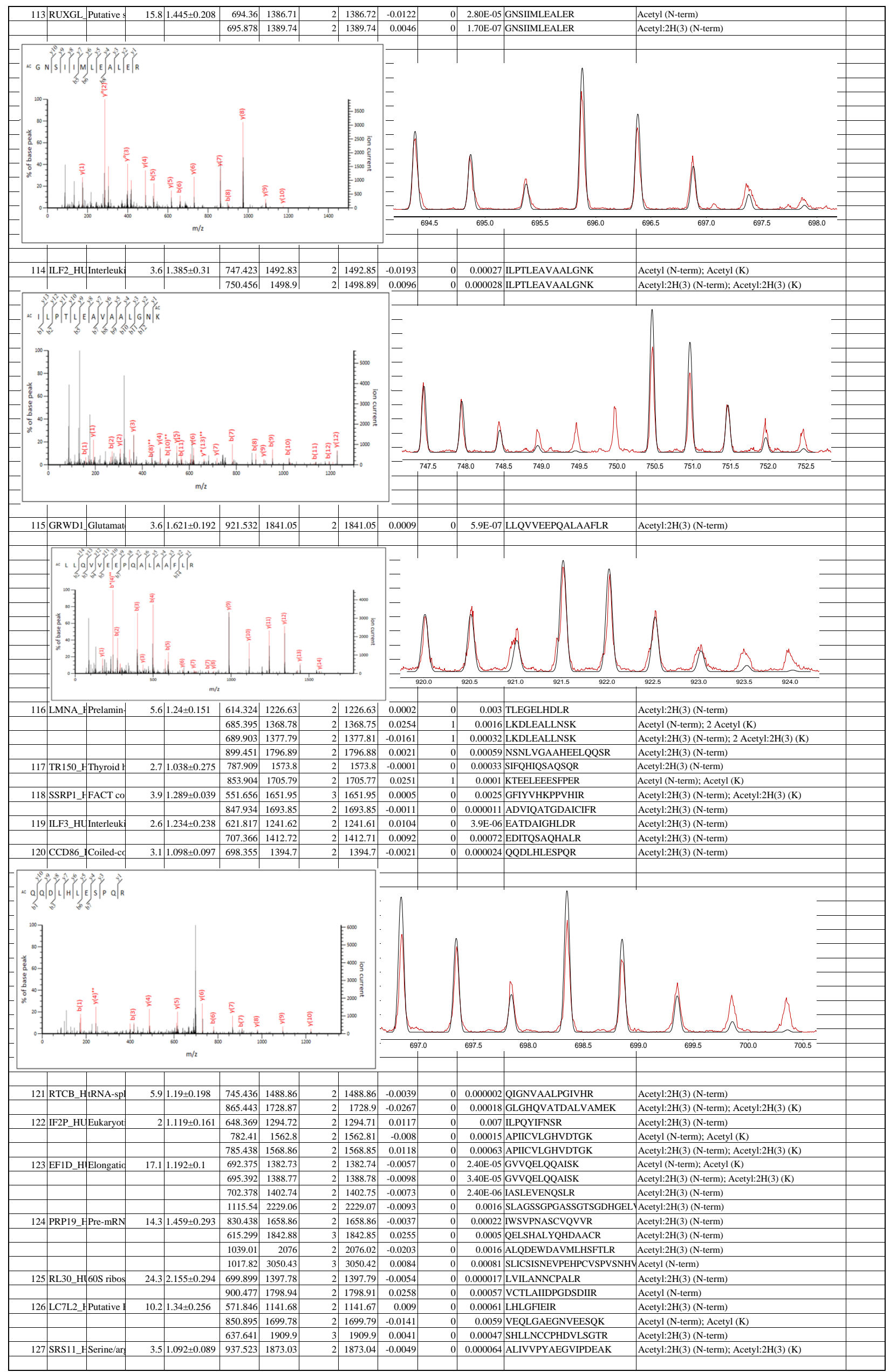









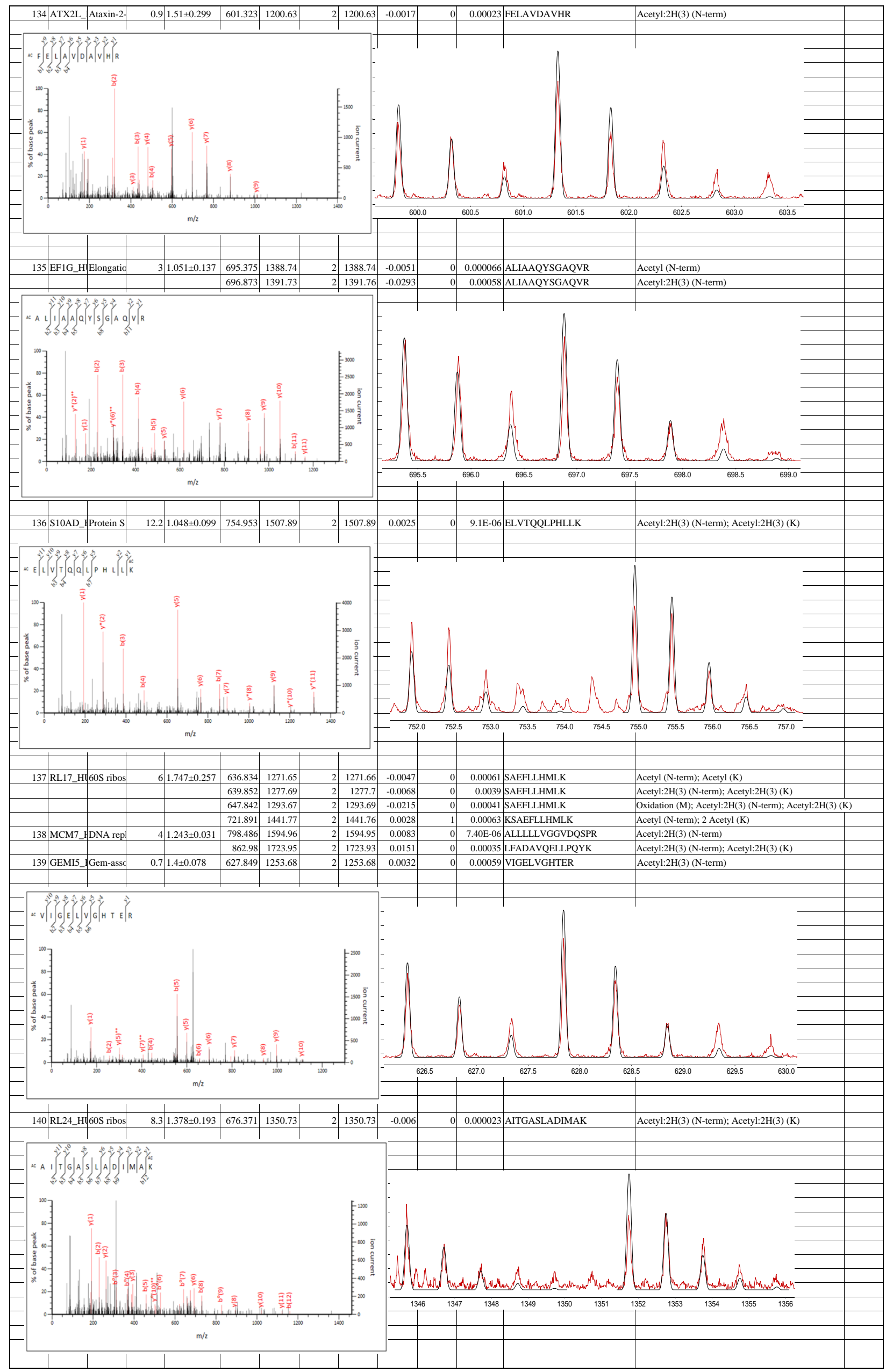




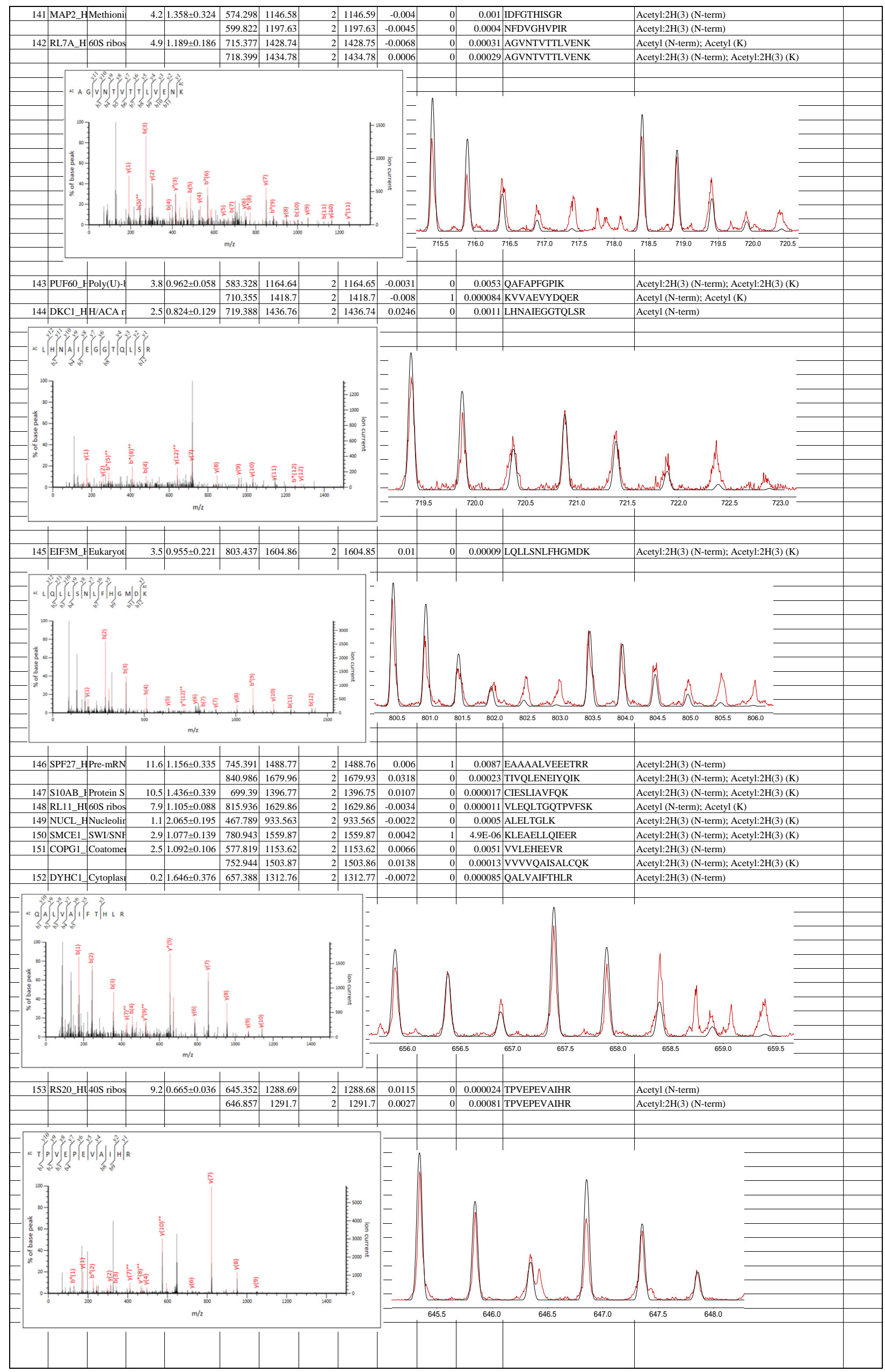




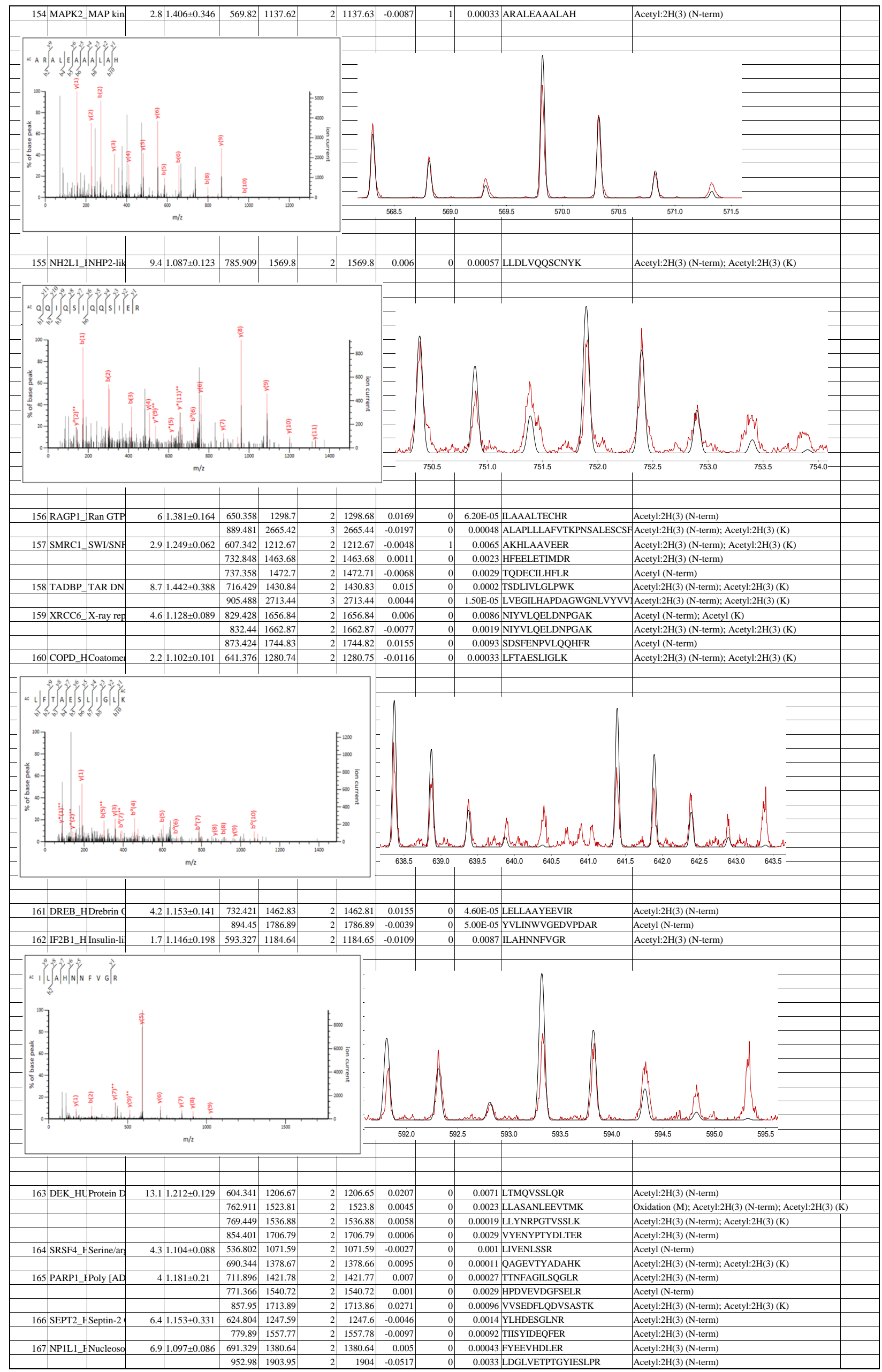




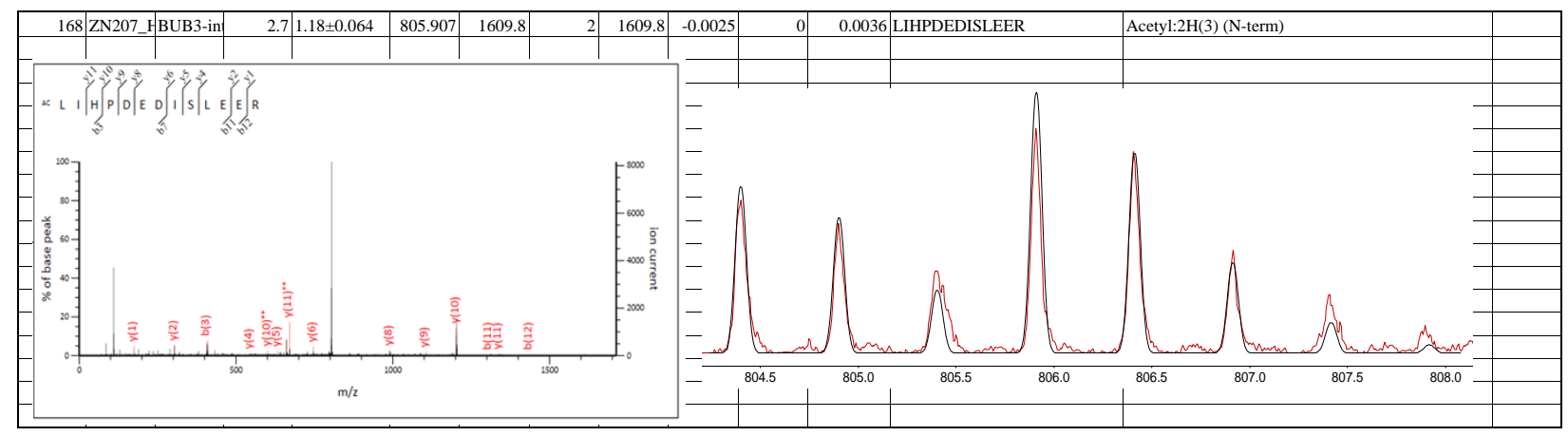


Table S2. GO information of proteins with MS quantitation ratios $\left(\mathrm{H}_{\mathrm{Pos}} / \mathrm{L}_{\mathrm{Neg}}\right)$ being larger than 1.50 or smaller than 0.67 .

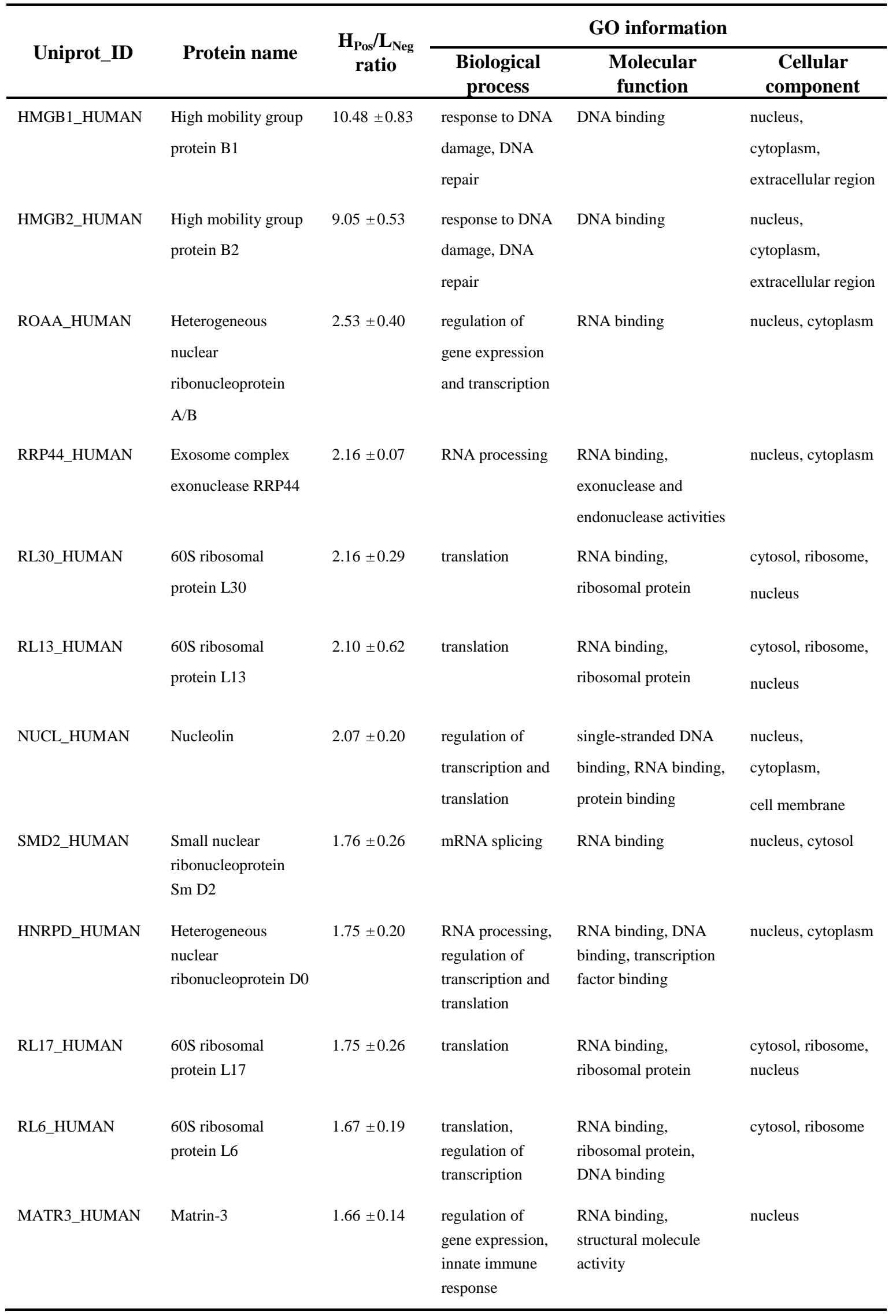


Table S2. Continued.

\begin{tabular}{|c|c|c|c|c|c|}
\hline \multirow{2}{*}{ Uniprot_ID } & \multirow{2}{*}{ Protein name } & \multirow{2}{*}{$\begin{array}{l}\mathbf{H}_{\mathrm{Pos}} / \mathbf{L}_{\mathrm{Neg}} \\
\quad \text { ratio }\end{array}$} & \multicolumn{3}{|c|}{ GO information } \\
\hline & & & $\begin{array}{c}\text { Biological } \\
\text { process }\end{array}$ & $\begin{array}{c}\text { Molecular } \\
\text { function }\end{array}$ & $\begin{array}{c}\text { Cellular } \\
\text { component }\end{array}$ \\
\hline DYHC1_HUMAN & $\begin{array}{l}\text { Cytoplasmic dynein } \\
1 \text { heavy chain } 1\end{array}$ & $1.65 \pm 0.38$ & $\begin{array}{l}\text { cell cycle, cell } \\
\text { division, transport }\end{array}$ & $\begin{array}{l}\text { Motor protein, ATP } \\
\text { binding, RNA binding }\end{array}$ & cytoskeleton \\
\hline DDX1_HUMAN & $\begin{array}{l}\text { ATP-dependent } \\
\text { RNA helicase } \\
\text { DDX1 }\end{array}$ & $1.63 \pm 0.26$ & $\begin{array}{l}\text { mRNA } \\
\text { processing, } \\
\text { transcription and } \\
\text { transcription } \\
\text { regulation, } \\
\text { response to DNA } \\
\text { damage, } \\
\text { double-stranded } \\
\text { break repair }\end{array}$ & $\begin{array}{l}\text { DNA binding, RNA } \\
\text { binding, RNA helicase } \\
\text { activity, exonuclease } \\
\text { activity, transcription } \\
\text { cofactor activity }\end{array}$ & nucleus, cytoplasm \\
\hline GRWD1_HUMAN & $\begin{array}{l}\text { Glutamate-rich WD } \\
\text { repeat-containing } \\
\text { protein } 1\end{array}$ & $1.62 \pm 0.19$ & $\begin{array}{l}\text { DNA replication, } \\
\text { nucleosome } \\
\text { assembly and } \\
\text { disassembly }\end{array}$ & $\begin{array}{l}\text { chromatin binding, } \\
\text { DNA binding, histone } \\
\text { binding, RNA binding }\end{array}$ & nucleus \\
\hline HNRDL_HUMAN & $\begin{array}{l}\text { Heterogeneous } \\
\text { nuclear } \\
\text { ribonucleoprotein } \\
\text { D-like }\end{array}$ & $1.61 \pm 0.04$ & $\begin{array}{l}\text { regulation of } \\
\text { transcription, } \\
\text { RNA processing }\end{array}$ & $\begin{array}{l}\text { DNA binding, RNA } \\
\text { binding, } \\
\text { transcriptional } \\
\text { activator and repressor }\end{array}$ & nucleus, cytoplasm \\
\hline IQGA1_HUMAN & $\begin{array}{l}\text { Ras } \\
\text { GTPase-activating- } \\
\text { like protein IQGAP1 }\end{array}$ & $1.59 \pm 0.31$ & $\begin{array}{l}\text { regulation of cell } \\
\text { cycle, signal } \\
\text { transduction }\end{array}$ & calmodulin binding & $\begin{array}{l}\text { cell membrane, } \\
\text { cytoplasm, nucleus }\end{array}$ \\
\hline TCP4_HUMAN & $\begin{array}{l}\text { Activated RNA } \\
\text { polymerase II } \\
\text { transcriptional } \\
\text { coactivator p15 }\end{array}$ & $1.59 \pm 0.19$ & $\begin{array}{l}\text { transcription } \\
\text { regulation }\end{array}$ & $\begin{array}{l}\text { ssDNA binding, } \\
\text { dsDNA binding, RNA } \\
\text { binding, transcription } \\
\text { coactivator activity }\end{array}$ & nucleus \\
\hline RL31_HUMAN & $\begin{array}{l}\text { 60S ribosomal } \\
\text { protein L31 }\end{array}$ & $1.58 \pm 0.40$ & translation & $\begin{array}{l}\text { RNA binding, } \\
\text { ribosomal protein }\end{array}$ & cytosol, ribosome \\
\hline RL23_HUMAN & $\begin{array}{l}\text { 60S ribosomal } \\
\text { protein } \mathrm{L} 23\end{array}$ & $1.58 \pm 0.21$ & $\begin{array}{l}\text { translation, } \\
\text { regulation of cell } \\
\text { cycle arrest, } \\
\text { regulation of } \\
\text { transcription and } \\
\text { gene expression }\end{array}$ & $\begin{array}{l}\text { RNA binding, } \\
\text { ribosomal protein, } \\
\text { transcription } \\
\text { coactivator binding, } \\
\text { ubiquitin ligase } \\
\text { inhibitor activity }\end{array}$ & $\begin{array}{l}\text { cytosol, ribosome, } \\
\text { nucleus }\end{array}$ \\
\hline CPSF6_HUMAN & $\begin{array}{l}\text { Cleavage and } \\
\text { polyadenylation } \\
\text { specificity factor } \\
\text { subunit } 6\end{array}$ & $1.57 \pm 0.25$ & mRNA processing & $\begin{array}{l}\text { mRNA binding, } \\
\text { ribosomal large } \\
\text { subunit binding }\end{array}$ & nucleus, cytoplasm \\
\hline RCC2_HUMAN & Protein RCC2 & $1.55 \pm 0.35$ & $\begin{array}{l}\text { cell cycle, cell } \\
\text { division, } \\
\text { regulation of cell } \\
\text { migration }\end{array}$ & $\begin{array}{l}\text { RNA binding, } \\
\text { guanine-nucleotide } \\
\text { releasing factor, } \\
\text { GTPase binding }\end{array}$ & $\begin{array}{l}\text { cell membrane, } \\
\text { cytoplasm, } \\
\text { cytoskeleton, } \\
\text { nucleus }\end{array}$ \\
\hline
\end{tabular}


Table S2. Continued.

\begin{tabular}{|c|c|c|c|c|c|}
\hline \multirow{2}{*}{ Uniprot_ID } & \multirow{2}{*}{ Protein name } & \multirow{2}{*}{$\begin{array}{l}\mathbf{H}_{\mathrm{Pos}} / \mathbf{L}_{\mathrm{Neg}} \\
\quad \text { ratio }\end{array}$} & \multicolumn{3}{|c|}{ GO information } \\
\hline & & & $\begin{array}{c}\text { Biological } \\
\text { process }\end{array}$ & $\begin{array}{c}\text { Molecular } \\
\text { function }\end{array}$ & $\begin{array}{c}\text { Cellular } \\
\text { component }\end{array}$ \\
\hline DDX21_HUMAN & $\begin{array}{l}\text { Nucleolar RNA } \\
\text { helicase } 2\end{array}$ & $1.53 \pm 0.46$ & $\begin{array}{l}\text { RNA processing, } \\
\text { transcription, innate } \\
\text { immune response }\end{array}$ & $\begin{array}{l}\text { ATP binding, RNA } \\
\text { binding, } \\
\text { ATP-dependent RNA } \\
\text { helicase activity }\end{array}$ & $\begin{array}{l}\text { cytoplasm, } \\
\text { mitochondrion, } \\
\text { nucleus }\end{array}$ \\
\hline IF4B_HUMAN & $\begin{array}{l}\text { Eukaryotic translation } \\
\text { initiation factor } 4 \mathrm{~B}\end{array}$ & $1.53 \pm 0.20$ & translation & $\begin{array}{l}\text { RNA binding, } \\
\text { ribosomal small } \\
\text { subunit binding }\end{array}$ & cytosol \\
\hline RL4_HUMAN & $\begin{array}{l}\text { 60S ribosomal protein } \\
\text { L4 }\end{array}$ & $1.52 \pm 0.20$ & translation & $\begin{array}{l}\text { RNA binding, } \\
\text { ribosomal protein }\end{array}$ & $\begin{array}{l}\text { cytosol, ribosome, } \\
\text { nucleus }\end{array}$ \\
\hline ATX2L_HUMAN & Ataxin-2-like protein & $1.51 \pm 0.30$ & $\begin{array}{l}\text { regulation of } \\
\text { cytoplasmic mRNA } \\
\text { processing body } \\
\text { assembly }\end{array}$ & $\begin{array}{l}\text { cadherin binding, } \\
\text { RNA binding }\end{array}$ & nucleus, cytoplasm \\
\hline DDX17_HUMAN & $\begin{array}{l}\text { Probable } \\
\text { ATP-dependent RNA } \\
\text { helicase DDX17 }\end{array}$ & $1.51 \pm 0.35$ & $\begin{array}{l}\text { mRNA splicing, } \\
\text { transcription and } \\
\text { transcription } \\
\text { regulation }\end{array}$ & $\begin{array}{l}\text { ATP binding, RNA } \\
\text { binding, RNA helicase } \\
\text { activity, transcription } \\
\text { coactivator activity }\end{array}$ & cytoplasm, nucleus \\
\hline VASP_HUMAN & $\begin{array}{l}\text { Vasodilator-stimulated } \\
\text { phosphoprotein }\end{array}$ & $1.50 \pm 0.46$ & $\begin{array}{l}\text { actin polymerization, } \\
\text { cell junction assembly }\end{array}$ & actin binding & $\begin{array}{l}\text { cell junction, cell } \\
\text { membrane, } \\
\text { cytoskeleton }\end{array}$ \\
\hline MYL6_HUMAN & $\begin{array}{l}\text { Myosin light } \\
\text { polypeptide } 6\end{array}$ & $1.50 \pm 0.29$ & $\begin{array}{l}\text { muscle contraction } \\
\text { muscle filament } \\
\text { sliding }\end{array}$ & $\begin{array}{l}\text { actin-dependent } \\
\text { ATPase activity, } \\
\text { calcium ion binding, } \\
\text { motor activity }\end{array}$ & $\begin{array}{l}\text { cytoskeleton, } \\
\text { cytosol }\end{array}$ \\
\hline RS20_HUMAN & $\begin{array}{l}40 \text { S ribosomal protein } \\
\text { S20 }\end{array}$ & $0.67 \pm 0.04$ & translation & $\begin{array}{l}\text { RNA binding, } \\
\text { ribosomal protein }\end{array}$ & cytosol, ribosome \\
\hline C2AIL_HUMAN & $\begin{array}{l}\text { CDKN2AIP } \\
\text { N-terminal-like } \\
\text { protein }\end{array}$ & $0.62 \pm 0.26$ & RNA metabolism & protein binding & nucleus \\
\hline T2FA_HUMAN & $\begin{array}{l}\text { General transcription } \\
\text { factor IIF subunit } 1\end{array}$ & $0.34 \pm 0.03$ & $\begin{array}{l}\text { transcription, } \\
\text { transcription } \\
\text { regulation and mRNA } \\
\text { splicing }\end{array}$ & $\begin{array}{l}\text { RNA binding, DNA } \\
\text { binding, transcription } \\
\text { factor binding, } \\
\text { transcription } \\
\text { coactivator activity }\end{array}$ & nucleus \\
\hline
\end{tabular}

\section{Additional Discussion:}

Apart from HMGB1 and HMGB2, 5 other proteins, hnRNP A/B, RRP44, RL30, RL13 and NCL, were identified to be significantly enriched by the positive probe, i.e. the cisplatin crosslinked ODN III. 
hnRNP A/B belongs to the heterogeneous nuclear ribonucleoprotein family, and has a diffuse nucleoplasmic distribution shuttling between nucleus and cytoplasm. $^{1}$ As an RNA-binding protein, hnRNP A/B has been found to participate in many aspects of RNA processing. ${ }^{1}$ Furthermore, hnRNP A/B is involved in regulation of transcription and interacts with both RNA and DNA. $^{1-3}$ A number of studies indicate that hnRNP A/B can modulate APOE promoter activity, ${ }^{4}$ regulate osteopontin transcription, ${ }^{5}$ and promote metastasis of hepatocellular carcinoma by transcriptionally activating Snail. ${ }^{6}$ hnRNP A/B also binds to flap endonuclease-1 (FEN-1), stimulating its nuclease activity and thus improving the efficiency of Okazaki fragment maturation in DNA replication. ${ }^{1,2}$

RRP44, the catalytic subunit of the RNA exosome complex, is a highly conserved $3^{\prime}$ to $5^{\prime}$ exoribonuclease and also possesses endoribonuclease activity. $^{7,8}$ In association with the exosome, RRP44 is implicated in RNA processing and degradation. ${ }^{8}$ It has diverse functions within RNA metabolism including mRNA quality control, regulation of gene expression and small RNA processing. ${ }^{9}$ A number of studies also correlate RRP44 to chromosome segregation, cell-cycle progression and spindle assembly. ${ }^{9}$ Moreover, the exosome has participated in targeting the activation-induced cytidine deaminase (AID) to both strands of transcribed DNA in mammalian B cells, where RRP44 may function in degrading the nascent RNA, thereby leaving the template strand as ssDNA substrate for AID as AID can only act on ssDNA. ${ }^{10}$

RL30 and RL13 are the structural constituent of ribosome binding to RNA and involved in the protein translation process. ${ }^{11,12}$

NCL is a multifunctional and highly abundant protein of nucleolus predominantly located in the nucleolus but also found in the nucleoplasm, cytoplasm and on the cell membrane. ${ }^{13,14}$ In addition to the canonical function in ribosome biogenesis, NCL has been demonstrated to be involved in many cellular processes, including chromatin remodeling, regulation of transcription 
and translation, cell proliferation, apoptosis regulation, DNA and RNA metabolism, stress response and DNA repair. ${ }^{14,15} \mathrm{NCL}$ possesses the ability to interact with DNA, RNA and proteins. It interacts with single-stranded DNA with higher affinity than with double-stranded DNA in vitro, ${ }^{13}$ and binds to the promoter of several genes in vivo like interleukin-9 receptor, ${ }^{16} \mathrm{VEGF}^{17}$ and HPV18 genes, ${ }^{18}$ controlling the transcription of these genes involved in cell proliferation and survival. NCL will translocate to nucleoplasm in response to genotoxic stress and subsequently play multiple functions in DNA damage response and repair. ${ }^{19}$ It has also been reported that NCL interacts with p53 and HDM2 to promote p53-HDM2 dissociation and HDM2 degradation, as a consequence, inhibiting HDM2-mediated p53 degradation and modulating p53 stabilization. ${ }^{19}$ The DNA damage repair functions of NCL is conferred by its interactions with DNA repair proteins, such as YB-1, PCNA, Rad51, RPA, APE1, DNA polymerase $\eta$ and topoisomerase I. $^{19,20}$

The five proteins described above have not been reported to interact with cisplatin-DNA intrastrand crosslinks previously, but they were differentially enriched by the positive probe in our study implying that they could specifically respond to cisplatin-DNA intrastrand crosslinks. We assume hnRNP A/B and NCL could interact with cisplatin-DNA damage via direct binding to cisplatin-DNA adducts or interaction with other DNA damage response proteins as they both possess multiple biological functions and form extensive interactions with other biomolecules. Since the cisplatin crosslinking causes partial unwinding in DNA duplex which is similar to the conformation during gene transcription when the DNA duplex is opened up, we propose that RRP44 may mediate the binding of other proteins to the ssDNA arising from the cisplatin crosslinking. Additionally, the five proteins all possess RNA-binding function. As discussed in the Discussion section of the manuscript, recently, an increasing number of RNA binding proteins have been demonstrated to be involved in DNA damage response, designated as DNA-damage response 
RNA-binding proteins (DDRBPs). ${ }^{21-23}$ DDRBPs act as both regulators and regulated factors of DNA damage response, however, so far the precise mechanism of their involvement in damage response remains unclear. Moreover, we do not rule out the possibility that the five proteins, in the context of responding to cisplatin-damaged DNA, acquires unique properties as compared to properties already described for them and that these unique properties are relevant to responding to cisplatin-damaged DNA. Further investigation and evidence are needed to elucidate the precise role of these proteins in cisplatin-DNA damage response.

Besides the 5 proteins described above with $\mathrm{H}_{\mathrm{Pos}} / \mathrm{L}_{\mathrm{Neg}}$ ratios greater than 2.00, we found that 22 proteins with $\mathrm{H}_{\mathrm{Pos}} / \mathrm{L}_{\mathrm{Neg}}$ ratios between 1.50 and 2.00 also showed slight enrichment by the positive probe such as DDX1 (ATP-dependent RNA helicase DDX1), GRWD1 (Glutamate-rich WD repeat-containing protein 1), HNRDL (Heterogeneous nuclear ribonucleoprotein D-like,) and PC4 (Activated RNA polymerase II transcriptional coactivator p15). DDX1 is involved in RNA metabolism and also act as transcription regulators (coactivators or corepressors) generally by interacting with transcription factors. ${ }^{24}$ Moreover, it participates in DNA damage repair, and facilitates the template-guided repair of transcriptionally active regions of the genome and promotes cell survival. ${ }^{25-27}$ GRWD1 regulates chromatin dynamics and binds to DNA replication origin, thereby playing a role in DNA replication. ${ }^{28} \mathrm{HNRDL}$ can bind to both double- and single-stranded DNA, and acts as a transcriptional regulator promoting both transcription repression and activation. ${ }^{29}$ PC4 is a DNA-binding protein and transcription coactivator that mediates functional interactions between upstream activators and the general transcriptional machinery. ${ }^{30,} 31$ Moreover, we have previously demonstrated that PC4 selectively interacts with crosslinked DNA by a trans-platinum anticancer complex. $^{32}$ Therefore, we assume that these 22 proteins can also specifically recognize cisplatin-crosslinked DNA. However, further investigation and 
evidence are still needed to elucidate the precise role of the above proteins in cisplatin-DNA damage response.

Most of these identified proteins are involved in transcription regulation. Only NCL and DDX1 are related to DNA damage repair, and no one was directly involved in DNA damage repair as the component of the repair machinery (e.g. NER proteins like XPA, XPC, RPA, XPG, etc.). We think the absence of DNA damage repair proteins may be attributed to the repair shielding of HMGB proteins. ${ }^{33}$ In vitro excision repair assays demonstrated that excision of the cisplatin 1,2-d(GpG) adduct by the human excision nuclease present in cell extracts, is inhibited in the presence of HMG-domain proteins. ${ }^{34}$ It was proposed that HMGB proteins mediate and potentiate cisplatin cytotoxicity by binding to cisplatin adducts and shielding them from repair. ${ }^{33,35}$ Consistent with this shielding model, purified replication protein A (RPA) cannot displace HMGB1 bound to cisplatin adducts. ${ }^{36}$ Besides, the high abundance of HMGB proteins (as you mentioned above) and their high affinity to bent DNA also promote the shielding effect. Moreover, as the cells we used in this study is cisplatin sensitive cells, the DNA repair system won't be very strong. Therefore, it is reasonable that we didn't find DNA damage repair proteins in this work since HMGB proteins shield repair proteins and help cisplatin to exert its anticancer activity whereas DNA damage repair proteins may mediate cisplatin resistance.

\section{References}

1. Han, S. P.; Tang, Y. H.; Smith, R., Functional diversity of the hnRNPs: past, present and perspectives. Biochem. J 2010, 430 (3), 379-392.

2. Chai, Q.; Zheng, L.; Zhou, M.; Turchi, J. J.; Shen, B., Interaction and Stimulation of Human FEN-1 Nuclease Activities by Heterogeneous Nuclear Ribonucleoprotein A1 in $\alpha$-Segment Processing during Okazaki Fragment Maturation. Biochemistry 2003, 42 (51), 15045-15052.

3. Guha, M.; Pan, H.; Fang, J.-K.; Avadhani, N. G.; Fox, T. D., Heterogeneous Nuclear Ribonucleoprotein A2 Is a Common Transcriptional Coactivator in the 
Nuclear Transcription Response to Mitochondrial Respiratory Stress. Mol. Biol. Cell 2009, 20 (18), 4107-4119.

4. Campillos, M.; Lamas, J. R.; García, M. A.; Bullido, M. J.; Valdivieso, F.; Vázquez, J., Specific interaction of heterogeneous nuclear ribonucleoprotein A1 with the -219 T allelic form modulates APOE promoter activity. Nucleic Acids Res. 2003, 31 (12), 3063-3070.

5. Gao, C.; Guo, H.; Wei, J.; Mi, Z.; Wai, P.; Kuo, P. C., S-Nitrosylation of Heterogeneous Nuclear Ribonucleoprotein A/B Regulates Osteopontin Transcription in Endotoxin-stimulated Murine Macrophages. J. Biol. Chem. 2004, 279 (12), 11236-11243.

6. Zhou, Z. J.; Dai, Z.; Zhou, S. L.; Hu, Z. Q.; Chen, Q.; Zhao, Y. M.; Shi, Y. H.; Gao, Q.; Wu, W. Z.; Qiu, S. J.; Zhou, J.; Fan, J., HNRNPAB Induces Epithelial-Mesenchymal Transition and Promotes Metastasis of Hepatocellular Carcinoma by Transcriptionally Activating SNAIL. Cancer Res. 2014, 74 (10), 2750-2762.

7. Lorentzen, E.; Basquin, J.; Tomecki, R.; Dziembowski, A.; Conti, E., Structure of the Active Subunit of the Yeast Exosome Core, Rrp44: Diverse Modes of Substrate Recruitment in the RNase II Nuclease Family. Mol. Cell 2008, 29 (6), 717-728.

8. Schneider, C.; Leung, E.; Brown, J.; Tollervey, D., The N-terminal PIN domain of the exosome subunit Rrp44 harbors endonuclease activity and tethers Rrp44 to the yeast core exosome. Nucleic Acids Res. 2009, 37 (4), 1127-1140.

9. Robinson, S.; Oliver, A.; Chevassut, T.; Newbury, S., The 3' to 5' Exoribonuclease DIS3: From Structure and Mechanisms to Biological Functions and Role in Human Disease. Biomolecules 2015, 5 (3), 1515-1539.

10. Basu, U.; Meng, F.-L.; Keim, C.; Grinstein, V.; Pefanis, E.; Eccleston, J.; Zhang, T.; Myers, D.; Wasserman, C. R.; Wesemann, D. R.; Januszyk, K.; Gregory, R. I.; Deng, H.; Lima, C. D.; Alt, F. W., The RNA Exosome Targets the AID Cytidine Deaminase to Both Strands of Transcribed Duplex DNA Substrates. Cell 2011, 144 (3), 353-363.

11. Castello, A.; Fischer, B.; Eichelbaum, K.; Horos, R.; Beckmann, B. M.; Strein, C.; Davey, N. E.; Humphreys, D. T.; Preiss, T.; Steinmetz, L. M.; Krijgsveld, J.; Hentze, M. W., Insights into RNA Biology from an Atlas of Mammalian mRNA-Binding Proteins. Cell 2012, 149 (6), 1393-1406.

12. Feo, S.; Davies, B.; Fried, M., The mapping of seven intron-containing ribosomal 
protein genes shows they are unlinked in the human genome. Genomics 1992, 13 (1), 201-207.

13. Ginisty, H.; Sicard, H.; Roger, B.; Bouvet, P., Structure and functions of nucleolin. J. Cell Sci. 1999, 112 (6), 761-772.

14. Berger, C. M.; Gaume, X.; Bouvet, P., The roles of nucleolin subcellular localization in cancer. Biochimie 2015, 113, 78-85.

15. Jia, W.; Yao, Z.; Zhao, J.; Guan, Q.; Gao, L., New perspectives of physiological and pathological functions of nucleolin (NCL). Life Sci. 2017, 186, 1-10.

16. Shang, Y.; Kakinuma, S.; Nishimura, M.; Kobayashi, Y.; Nagata, K.; Shimada, Y., Interleukin-9 receptor gene is transcriptionally regulated by nucleolin in T-Cell lymphoma cells. Mol. Carcinogenesis 2011, 51 (8), 619-627.

17. Uribe, D. J.; Guo, K.; Shin, Y. J.; Sun, D., Heterogeneous nuclear ribonucleoprotein $\mathrm{K}$ and nucleolin as transcriptional activators of the vascular endothelial growth factor promoter through interaction with secondary DNA structures. Biochemistry 2011, 50 (18), 3796-806.

18. Grinstein, E.; Wernet, P.; Snijders, P. J. F.; Rösl, F.; Weinert, I.; Jia, W.; Kraft, R.; Schewe, C.; Schwabe, M.; Hauptmann, S.; Dietel, M.; Meijer, C. J. L. M.; Royer, H.-D., Nucleolin as Activator of Human Papillomavirus Type 18 Oncogene Transcription in Cervical Cancer. J. Exp. Med. 2002, 196 (8), 1067-1078.

19. Scott, D. D.; Oeffinger, M., Nucleolin and nucleophosmin: nucleolar proteins with multiple functions in DNA repair. Biochem. Cell Biol. 2016, 94 (5), 419-432.

20. De, A.; Donahue, S. L.; Tabah, A.; Castro, N. E.; Mraz, N.; Cruise, J. L.; Campbell, C., A novel interation of nucleolin with Rad51. Biochem. Biophys. Res. Commun. 2006, 344 (1), 206-213.

21. Kai, M., Roles of RNA-Binding Proteins in DNA Damage Response. Int. J. Mol. Sci. 2016, 17 (3), 310.

22. Wickramasinghe, V. O.; Venkitaraman, A. R., RNA Processing and Genome Stability: Cause and Consequence. Mol. Cell 2016, 61 (4), 496-505.

23. Dutertre, M.; Vagner, S., DNA-Damage Response RNA-Binding Proteins (DDRBPs): Perspectives from a New Class of Proteins and Their RNA Targets. J. Mol. Biol. 2017, 429 (21), 3139-3145.

24. Ishaq, M.; Ma, L.; Wu, X.; Mu, Y.; Pan, J. a.; Hu, J.; Hu, T.; Fu, Q.; Guo, D., The DEAD-box RNA helicase DDX1 interacts with RelA and enhances nuclear factor kappaB-mediated transcription. J. Cell. Biochem. 2009, 106 (2), 296-305. 
25. Li, L.; Monckton, E. A.; Godbout, R., A Role for DEAD Box 1 at DNA Double-Strand Breaks. Mol. Cell. Biol. 2008, 28 (20), 6413-6425.

26. Li, L.; Germain, D. R.; Poon, H.-Y.; Hildebrandt, M. R.; Monckton, E. A.; McDonald, D.; Hendzel, M. J.; Godbout, R., DEAD Box 1 Facilitates Removal of RNA and Homologous Recombination at DNA Double-Strand Breaks. Mol. Cell. Biol. 2016, 36 (22), 2794-2810.

27. He, Y.; Yuan, J.; Qiao, Y.; Wang, D.; Chen, W.; Liu, X.; Chen, H.; Guo, Z., The role of carrier ligands of platinum(ii) anticancer complexes in the protein recognition of Pt-DNA adducts. Chem. Commun. 2015, 51 (74), 14064-14067.

28. Sugimoto, N.; Maehara, K.; Yoshida, K.; Yasukouchi, S.; Osano, S.; Watanabe, S.; Aizawa, M.; Yugawa, T.; Kiyono, T.; Kurumizaka, H.; Ohkawa, Y.; Fujita, M., Cdt1-binding protein GRWD1 is a novel histone-binding protein that facilitates MCM loading through its influence on chromatin architecture. Nucleic Acids Res. 2015, 43 (12), 5898-5911.

29. Tsuchiya, N.; Kamei, D.; Takano, A.; Matsui, T.; Yamada, M., Cloning and Characterization of a cDNA Encoding a Novel Heterogeneous Nuclear Ribonucleoprotein-Like Protein and Its Expression in Myeloid Leukemia Cells. $J$. Biochem. 1998, 123 (3), 499-507.

30. Ge, H.; Roeder, R. G., Purification, cloning, and characterization of a human coactivator, PC4, that mediates transcriptional activation of class II genes. Cell 1994, $78(3), 513-523$.

31. Kretzschmar, M.; Kaiser, K.; Lottspeich, F.; Meisterernst, M., A novel mediator of class II gene transcription with homology to viral immediate-early transcriptional regulators. Cell 1994, 78 (3), 525-534.

32. Du, Z.; Luo, Q.; Yang, L.; Bing, T.; Li, X.; Guo, W.; Wu, K.; Zhao, Y.; Xiong, S.; Shangguan, D.; Wang, F., Mass spectrometric proteomics reveals that nuclear protein positive cofactor PC4 selectively binds to cross-linked DNA by a trans-platinum anticancer complex. J. Am. Chem. Soc. 2014, 136 (8), 2948-51.

33. Kartalou, M.; Essigmann, J. M., Recognition of cisplatin adducts by cellular proteins. Mutat. Res. 2001, 478 (1), 1-21.

34. Huang, J. C.; Zamble, D. B.; Reardon, J. T.; Lippard, S. J.; Sancar, A., HMG-domain proteins specifically inhibit the repair of the major DNA adduct of the anticancer drug cisplatin by human excision nuclease. Proc. Natl. Acad. Sci. U.S.A. 1994, 91 (22), 10394. 
35. Awuah, S. G.; Riddell, I. A.; Lippard, S. J., Repair shielding of platinum-DNA lesions in testicular germ cell tumors by high-mobility group box protein 4 imparts cisplatin hypersensitivity. Proc. Natl. Acad. Sci. U.S.A. 2017, 114 (5), 950.

36. Patrick, S. M.; Turchi, J. J., Human Replication Protein A Preferentially Binds Cisplatin-Damaged Duplex DNA in Vitro. Biochemistry 1998, 37 (24), 8808-8815. 